\title{
LOS ANTIGUOS CAFÉS DE ZARAGOZA EN EL SIGLO XIX
}

\author{
Mónica Vázquez Astorga \\ Universidad de Zaragoza"
}

RESUMEN: En este texto nos proponemos un recorrido, dentro del contexto de la época, por los antiguos cafés con los que contó la ciudad de Zaragoza a lo largo del siglo XIX. Interesa especialmente analizar su evolución y características desde finales del siglo XVIII (cuando comienzan a conformarse como espacios de reunión y entretenimiento) hasta el año 1902 (cuando se cierra su edad de oro y se halla plenamente establecido el café lujoso y fastuoso como lugar preferente de la sociedad burguesa). Estos establecimientos públicos vinieron a enriquecer la oferta de ocio en la ciudad y muchos de ellos desempeñaron hasta su desaparición en el siglo XX un papel relevante como espacios de encuentro social y de celebración de tertulias.

Palabras claves: Cafés históricos, espacios de reunión y sociabilidad, arquitectura del siglo XIX, Zaragoza contemporánea.

\section{THE OLD $19^{\text {TH }}$ CENTURY VINTAGE CAFÉS OF ZARAGOZA}

ABSTRACT: In this article we would like to show our readers around the old vintage cafés that the city of Zaragoza held in the $19^{\text {th }}$ century. We are highly interested in analysing their evolution and their main features from the end of the $18^{\text {th }}$ century, when they began to be considered public meeting and entertaining venues until 1902, when their golden age comes to an end and they are regarded as luxurious and sumptuous venues for the bourgeoisie. These public businesses

\footnotetext{
* Este artículo se ha llevado a cabo dentro del Grupo de Investigación Consolidado del Departamento de Historia del Arte de la Universidad de Zaragoza Patrimonio Artístico en Aragón (cofinanciado por el Gobierno de Aragón y el Fondo Social Europeo, Programa Operativo 2007-2013, y bajo la dirección de la Dra. María Isabel Álvaro Zamora como investigadora principal); y del Proyecto de investigación Museos y barrios artísticos: arte público, artistas e instituciones (código HAR2012-38899-C02-01, financiado por el Ministerio de Ciencia e Innovación), con el Dr. Jesús Pedro Lorente como investigador principal.
} 
enriched the entertainment offer of the city, and many of them had a relevant role as social meeting venues and debate circles until they ran out of business in the $20^{\text {th }}$ century.

Keywords: Historical cafes, places for meeting and sociability, 19th century architecture, Contemporary Saragossa.

\section{Presentación}

En estas líneas nos proponemos un recorrido histórico por la Zaragoza del siglo XIX y, en concreto, por sus antiguos cafés, que, además de locales públicos en los que se consumía café u otras bebidas, se convirtieron en verdaderos lugares de reunión, tertulias y actuaciones artísticas, dado que estar en un café no debe entenderse solo como una manera de pasar el tiempo, o dejarlo pasar, sin más ${ }^{1}$. Para ello, partimos de finales del siglo XVIII, cuando comienza a conformarse el café como espacio de entretenimiento y encuentro social, y presentamos su evolución a lo largo del siglo XIX, centrándonos en el momento de su máximo esplendor, es decir, en la denominada Edad de Oro del café, que fue, en nuestro país, la de los años de la restauración monárquica y de la regencia de María Cristina, cerrando así nuestro discurso en 1902, fecha en la que ya se halla plenamente conformado el café como espacio lujoso y preferente de la sociedad burguesa. Además, los cafés fueron, sobre todo en el siglo XIX, un lugar de intercambio de ideas en libertad ${ }^{2}$, y en sus tertulias se originaron conspiraciones, asociaciones o movimientos artísticos y culturales.

Como señala Antonio Bonet Correa, el café se introdujo en Europa en el siglo XVII (austriacos, franceses e italianos fueron los primeros en degustar el llamado "néctar" o "vino de los árabes"), y a nuestro país llegó más tarde (tanto la afición a tomar esta aromática bebida como la aparición del establecimiento público), en el siglo XVIII, a la par que las ideas ilustradas ${ }^{3}$. De este modo, el café, a diferencia de los salones privados, era el lugar al que podían acudir personas de distintas clases y condiciones, como reflejo de la naciente democracia en la edad contemporánea.

A la hora de emprender esta investigación nos hemos encontrado con la dificultad de la ausencia de planos correspondientes a las intervenciones acometidas en los locales ocupados por estos establecimientos públicos, limitándose

1. MARTí MONTERDE, A., Poética del Café. Un espacio de la modernidad literaria europea. Barcelona, 2007, p. 19.

2. SHATTUCK, R., La época de los banquetes. Orígenes de la vanguardia en Francia: de 1885 a la Primera Guerra Mundial. Madrid, 1991, p. 24.

3. BONET CORREA, A., Los cafés históricos. Madrid, 2012, p. 15. 
nuestros hallazgos a diseños de portadas; debido a que en estos años las licencias municipales para la instalación o reforma de recintos comerciales e industriales exigían únicamente la presentación del plano de la fachada. Asimismo, muchos de estos espacios tenían decoración en sus interiores, pero esa pintura ornamental tampoco ha llegado hasta nosotros, siendo, por tanto, escasas las fuentes con las que contamos para poder tener un conocimiento en profundidad de estos establecimientos zaragozanos, que seguían particularmente los modelos creados en París.

Aún permanece en el recuerdo de muchos zaragozanos y forasteros el nombre de alguno de esos cafés históricos, que fundados en el siglo XIX continuaron abiertos hasta bien entrado el siglo XX, como el café de Ambos Mundos, si bien poco se sabe en realidad de estos establecimientos por cuya solera Zaragoza llegó a ser conocida en la época como la "ciudad de los cafés". De hecho, ya en 1867 ascendía a 21 la cifra de cafés existentes en la capital aragonesa ${ }^{4}$. Por este motivo, con estas páginas pretendemos recuperar para el recuerdo esos primeros cafés zaragozanos, analizando su origen, desarrollo e impacto cultural y social en la ciudad a lo largo del siglo XIX. Para ello destacamos tres etapas en su evolución: la primera, en la que abordamos su remiso desarrollo en la primera mitad de la centuria, hundiendo sus raíces en el siglo XVIII; la segunda, en la que nos ocupamos de los años centrales del siglo, en los que se inicia su conformación como espacios de lujo; y la tercera, que se extiende en las tres últimas décadas del siglo y primeros años del siglo XX, en la que tratamos de su época de máximo apogeo y esplendor.

\section{Estampa de los primeros cafés}

La ciudad de Zaragoza contaba a finales del siglo XVIII con varias posadas, mesones y fondas ${ }^{5}$, que desempeñaron el papel de lugares de reunión.

A estos establecimientos cabe sumar los cafés (que tuvieron como antecedente los mentideros y como precursoras las botillerías), y de los que en estas fechas existían en Zaragoza tres, situados todos en la calle del Coso (una de las más espaciosas y transitadas vías de la ciudad), y denominados café de Carmen, café de Gimeno y café de la Reunión. El café de Carmen, que parece ser el más antiguo (estimándose su fundación a mediados de siglo), se hallaba ubicado junto al tea-

4. Archivo Municipal de Zaragoza [A.M.Z.], Sección de Estadística, Incidencias, Caja 1.305, expediente núm. 2: "Para que se manifieste a la mayor brevedad posible el número de tertulias públicas, villares, cafés y tabernas que existan en esta ciudad, expresando el número de personas que por término medio concurren a cada uno de estos establecimientos", 1868.

5. Las posadas y fondas zaragozanas ( $y$ aragonesas, en general) han sido estudiadas por PARRA DE MAS, S., Fondas, hoteles y banquetes en la Zaragoza del siglo XIX (Cuadernos de Aragón, núm. 38. Discurso de ingreso en la Academia Aragonesa de Gastronomía. Contestación por D. Manuel García Guatas). Zaragoza, 2008, pp. 42-58 y 59-73. 
tro municipal (denominado teatro Principal, cuyos límites en esos momentos eran las calles del Coso, por el Sur, Graneros -actual de Eusebio Blasco-, por el Este, y Don Jaime I, por el Oeste) $)^{6}$ y en sus inmediaciones se encontraba el café de Gimeno $^{7}$. Por su parte, el café de la Reunión estaba emplazado en un inmueble de la calle del Coso, enfrente de la de San Gil y junto a la antigua Casa de Comedias (regentada por el Hospital de Nuestra Señora de Gracia) ${ }^{8}$, por tanto muy próximo al solar que ocupaban los dos primeros establecimientos citados.

Por espacio de mucho tiempo, Zaragoza, y a diferencia de otras ciudades españolas, sólo poseyó estos tres lugares de encuentro y esparcimiento, caracterizados por sus reducidas dimensiones y atmósfera pesada (debida al efecto de la iluminación a gas y al humo del tabaco). A principios de la década de los sesenta del siglo XIX únicamente subsistía el acreditativo café de Gimeno ${ }^{9}$, en calle del Coso, siempre muy concurrido. Pero tras el final de la Guerra de la Independencia (1808-1814), y a pesar de la lastimosa economía municipal, habían ido surgiendo paulatinamente otros cafés como el de Buenavista ${ }^{10}$ y el

6. En relación con este entorno urbano del teatro, es preciso mencionar que, hasta mediados del siglo XIX, la calle de Don Jaime I transcurría según un trazado irregular dividida en varios sectores independientemente denominados: de San Gil (Nueva y Vieja), de San Pedro, plaza de San Martín, de la Virgen del Rosario y de la Cuchillería. En 1857 el Ayuntamiento decidió rectificar las citadas calles, dándoles una alineación uniforme y nombre único, el de calle de Don Jaime I, que se inició en la plaza de la Seo continuando hacia el Sur hasta el Coso. YESTE NAVARRO, I., "Transformaciones en el entorno urbano del Teatro Principal". Artigrama 13 (1998), p. 134.

7. En el periódico Diario de Zaragoza, en el año de su fundación en 1797, se menciona un café en la casa de Antonio Ximeno, situada en calle del Coso. Diario de Zaragoza, Zaragoza, lunes 24 de abril de 1797, "Noticias particulares de Zaragoza", p. 372.

A principios de 1818 el inmueble donde estaba ubicado el café y botillería de Gimeno fue reformado, por lo que tuvo que trasladarse temporalmente a un edificio emplazado en calle de San Gil, abriendo sus puertas poco después completamente renovado en su ubicación original. Diario de Zaragoza, Zaragoza, viernes 13 de marzo de 1818, "Noticias particulares de Zaragoza", p. 288.

8. Como señala Amparo Martínez, durante más de doscientos años funcionó en Zaragoza una Casa de Comedias que estuvo situada en el Coso, y que se había abierto al público en 1590. Su dilatada trayectoria quedó truncada el 12 de noviembre de 1778 a causa de un incendio. Hubo que esperar a finales de 1797 para que se considerase conveniente levantar un nuevo edificio para espectáculos teatrales. De este modo, el 25 de agosto de 1799 tuvo lugar la inauguración del nuevo teatro de la ciudad (que posteriormente recibió el nombre de teatro Principal), emplazado en el Coso, frente al solar que había ocupado la antigua Casa de Comedias. Sobre este tema, véase MARTínEZ HERRANZ, A., "El Teatro Principal de Zaragoza. Arte e Historia". Artigrama 13 (1998), p. 18; MARTíNEZ HERRANZ, A., Teatro Principal. Zaragoza, 1999, pp. 13-20; y MARTÍNEZ HERRANZ, A., La arquitectura teatral en Zaragoza. De la Restauración borbónica a la Guerra Civil (1875-1939), vol. I. Zaragoza, 2003, pp. 30-100.

9. Guía de Zaragoza: o séa breve noticia de las antigüedades, establecimientos públicos, oficinas y edificios que contiene. Zaragoza, 1860, p. 103.

10. Diario de Zaragoza, Zaragoza, sábado 30 de noviembre de 1816, "Noticias particulares de Zaragoza", p. 1.340. 
del Sol11, situados en el Coso, o el café de la Constitución ${ }^{12}$ (luego denominado café Español)13, ubicado en la cercana plaza de la Constitución (actual plaza de España), todos ellos abiertos ya en la década de los diez.

Tras el fallecimiento del rey Fernando VII, en 1833, su cuarta esposa María Cristina de Borbón asumió la regencia de España en nombre de su hija Isabel, que fue proclamada mayor de edad en 1843. Desde 1833, con la disolución del Antiguo Régimen y la transición hacia nuevas formas económicas y sociales, se conformó en Aragón una burguesía emergente; hecho que ayuda a comprender la historia decimonónica en este territorio ${ }^{14}$. Tras un período de turbulencia política se abrieron otros cafés, especialmente en los primeros años de la década de los treinta (sobre todo antes del inicio de la primera guerra carlista, 1833-1839), entre los que se encontraban los siguientes: en 1830, el café de Sola (calle de San Gil) ${ }^{15}$; en 1831, el café de la Estrella (calle alta de San Pedro, núm. 2) ${ }^{16}$; en 1832, el café de Casanova (frente a la Virgen del Rosario) ${ }^{17}$; en 1833, otros dos nuevos establecimientos en calle del Coso: uno, inaugurado a principios de febrero, situado junto a la puerta del teatro Principal (en el núm. 35) $)^{18}$-que a partir del 31 de octubre de 1834 recibiría el título de café del Sable ${ }^{19}-$, y otro, abierto el 23 de junio, ubicado en la casa núm. 21 de esta

11. Diario de Zaragoza, Zaragoza, miércoles 16 de diciembre de 1818, "Noticias particulares de Zaragoza", p. 1.400.

El café del Sol (calle del Coso, núm. 14) pasó a denominarse café de Aparicio en julio de 1835. Diario de Zaragoza, Zaragoza, domingo 5 de julio de 1835, "Noticias particulares de Zaragoza", p. 4.

12. Diario Constitucional de Zaragoza, Zaragoza, jueves 15 de junio de 1820, "Noticias particulares de Zaragoza", p. 4.

13. Este café estaba situado junto al palacio de la Diputación Provincial. Diario Constitucional de Zaragoza, Zaragoza, sábado 23 de septiembre de 1841, "Anuncios", p. 4.

14. FERNÁNDEZ CLEMENTE, E. y FORCADELL ÁLVAREZ, C., Aragón contemporáneo. Estudios. Madrid, 1986, p. 37.

15. Diario de Zaragoza, Zaragoza, martes 2 de febrero de 1830, "Noticias particulares de Zaragoza", p. 4.

Este establecimiento se trasladó, en agosto de 1849, al inmueble contiguo al local que ocupaba en calle de San Gil. En 1850 se especializó como confitería, cambiando de gestión a finales de esa década. Diario de Zaragoza. Periódico de Avisos, Zaragoza, domingo 19 de agosto de 1849, "Sección Local", p. 3.

16. Diario de Zaragoza, Zaragoza, domingo 18 de septiembre de 1831, "Noticias particulares de Zaragoza", p. 6.

17. Diario de Zaragoza, Zaragoza, jueves 3 de febrero de 1832, "Noticias particulares de Zaragoza", p. 132.

18. Diario de Zaragoza, Zaragoza, sábado 16 de febrero de 1833, "Noticias particulares de Zaragoza", p. 187.

19. Diario de Zaragoza, Zaragoza, viernes 31 de octubre de 1834, "Noticias particulares de Zaragoza", p. 4. 
vía urbana, esquina a la de Puerta Cineja o Cinegia ${ }^{20}$, conocido como café de San Fernando ${ }^{21}$; en 1834, el café del Ángel (calle de la Cuchillería, núm. 14)22; en febrero de 1838, el café del Comercio (calle del Coso, próximo al palacio de los condes de Sástago ${ }^{23}$; en mayo de 1838, el café de Oto (situado en la Ilamada Casa de las Monas -próxima al edificio de la Audiencia-, en el núm. 1 de la desaparecida calle de Cerdán) ${ }^{24}$; o en junio de 1838, y un poco más alejado del anterior entorno, se instaló un café (con el título de Moreno) y una posada en el edificio del suprimido convento de Altabás, en el Arrabal25. Estos establecimientos, de pequeñas dimensiones y de gran concurrencia, estuvieron de moda en esta época. En ellos no sólo se consumía café, sino que además se vendían raciones de comida y se ofrecían otros productos como licores, ponches, aguas heladas, helados, sorbetes y turrones.

La vida de estos cafés fue, por lo general, breve, puesto que los locales que ocupaban se arrendaban o traspasaban con frecuencia, o se les cambiaba de nombre, a causa de la situación de desconcierto y agitación existente a nivel político y social.

Además, había otros establecimientos como las fondas que, en ocasiones, acogían un café en sus instalaciones, estando entre los más notables de la ciudad los cafés de la fonda de las Cuatro Naciones ${ }^{26}$ y de la fonda de Europa, emplazada esta última, en 1843, en pleno centro urbano y, en concreto, en par-

20. La Puerta Cineja o Cinegia fue una de las puertas romanas de la ciudad y estuvo emplazada al Sur de la misma, en el Coso, en la embocadura de la actual calle de los Mártires, en la plaza de España.

21. Diario de Zaragoza, Zaragoza, domingo 23 de junio de 1833, "Noticias particulares de Zaragoza", p. 4.

22. Diario de Zaragoza, Zaragoza, jueves 27 de marzo de 1834, "Noticias particulares de Zaragoza", p. 4.

Este café tuvo una corta existencia, hasta septiembre de 1836.

23. Diario Constitucional de Zaragoza, Zaragoza, jueves 22 de febrero de 1838, "Noticias particulares de Zaragoza", p. 4.

Este café estuvo abierto durante diez años. Diario de Zaragoza. Periódico de Avisos, Zaragoza, lunes 1 de enero de 1848, "Sección Local", p. 2.

24. Diario Constitucional de Zaragoza, Zaragoza, domingo 13 de mayo de 1838, "Noticias particulares de Zaragoza", p. 4.

En las proximidades de este establecimiento estuvo situada la antigua y acreditada Casa de Peña, en la calle de la Cedacería (posteriormente calle de las Escuelas Pías), frente a los Escolapios. En esta misma calle de las Escuelas Pías se emplazó en 1861 el café de la Amistad, así como el café del Recreo.

25. Diario Constitucional de Zaragoza, Zaragoza, martes 5 de junio de 1838, "Noticias particulares de Zaragoza", p. 4.

26. La fonda de las Cuatro Naciones (creada hacia 1840) era propiedad de Gaudencio Fortis. Diario de Zaragoza. Periódico de Avisos, Zaragoza, miércoles 30 de mayo de 1849, "Sección Local", p. 4. 


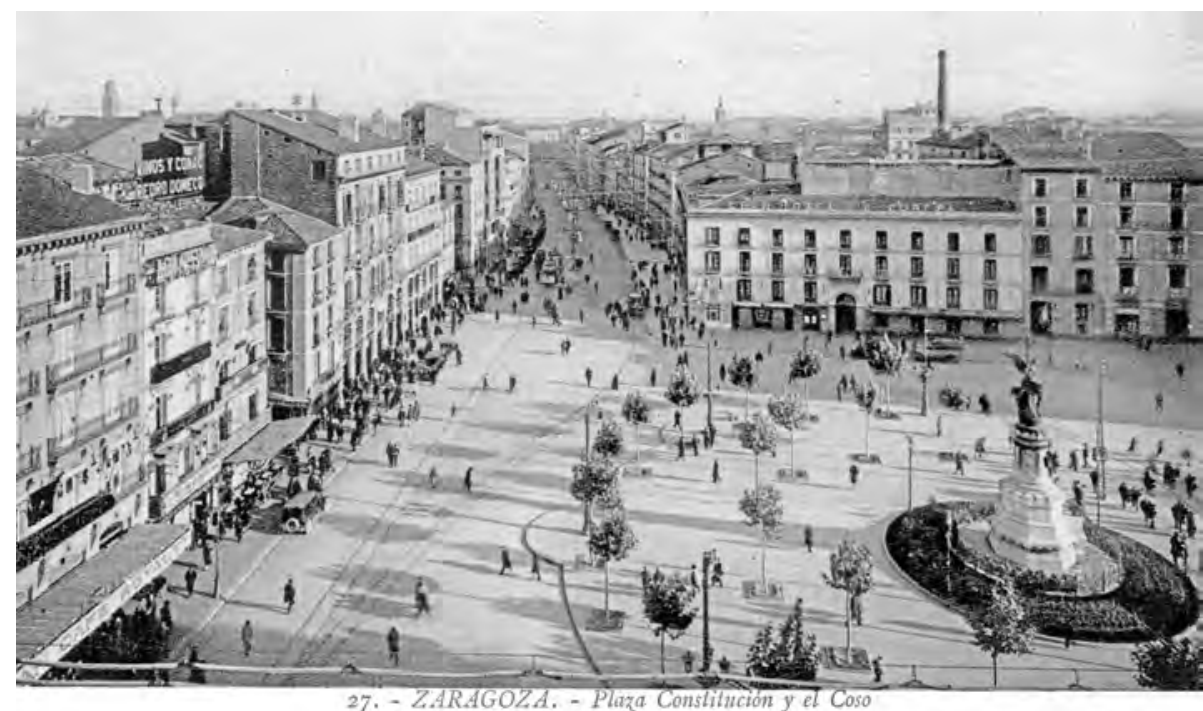

Figura 1. Aspecto de la plaza de la Constitución (hoy de España) y del Coso (con el Hotel Europa al fondo a la derecha), hacia la década de los diez del siglo XX (Archivo Municipal de Zaragoza, signatura: 00105).

te de los terrenos del Hospital de Nuestra Señora de Gracia ${ }^{27}$. Se alzaba en el solar en el que actualmente se encuentra una sucursal del Banco de España, y tenía su entrada por la plaza de la Constitución (en la actualidad plaza de España $)^{28}$ y por la calle del Coso (Fig. 1). En lo que respecta a su café, cabe decir que

Con el nombre de fonda de las Cuatro Naciones existían, además de en Zaragoza, en Barcelona, Madrid o en Badajoz. GARCíA GUATAS, M., De boca a boca. Comer en Aragón en los siglos contemporáneos (Cuadernos de Aragón, núm. 52. Discurso de ingreso en la Academia Aragonesa de Gastronomía y contestación a cargo del académico D. Guillermo Fatás Cabeza). Zaragoza, 2012, p. 20.

27. Diario Constitucional de Zaragoza, Zaragoza, sábado 26 de agosto de 1843, "Anuncios", p. 4.

28. En agosto de 1851, el dueño de la fonda de Europa, Gaudencio Zoppetti, solicitó al Ayuntamiento licencia para abrir una puerta en la fachada de este edificio a la plaza de la Constitución, siéndole concedida en ese mismo mes. A.M.Z., Sección de Policía Urbana, Licencias para edificar, Caja 1.723, expediente núm. 2: "Expediente instruido a instancias de Gaudencio Zopeti solicitando autorización para abrir una puerta en la fonda de Europa", 1851.

En abril de 1859, este mismo propietario pidió autorización para reformar el exterior del edificio y, en concreto, la fachada que presentaba a la plaza, conforme al plano redactado por el arquitecto José de Yarza. El Ayuntamiento le concedió licencia para estas obras, teniendo que introducir alguna modificación en el proyecto. A.M.Z., Sección de Policía Urbana, Licencias de obras en fachadas, Caja 1.733, expediente núm. 342: “D. Gaudencio Zopetti para que se le permita rectificar la fachada de la fonda de Europa, sita en la plaza de la Constitución", 1859. 
fue fundado con el título de café de Europa (con entrada por plaza de la Constitución, núm. 8) tras la reforma interior y exterior que fue acometida en este edificio a finales de 1863. Así, la planta baja de esta casa fue decorada con todo lujo como café, y contiguo al mismo se situó un salón-restaurant.

La década de los cuarenta se abrió con la visita a Zaragoza de la reina María Cristina de Borbón y su hija Isabel, en junio de 1840, y, en el plano económi$\mathrm{co}$, con la evidencia de los primeros pasos para conformar un tejido industrial en la ciudad. De este modo, se fueron instalando fábricas de cerveza, licores, aguardientes y refrescos gaseosos, como la fundada en 1841 por Joaquín Mairal (propietario también del café de la Constancia) ${ }^{29}$ en el Salón de Santa Engracia (actual paseo de la Independencia) ${ }^{30}$. En 1842, y bajo la denominación de las Delicias, Joaquín Mairal estableció un café en el mismo inmueble de la fábrica de cerveza citada ${ }^{31}$, en el que actuaba una orquesta desde las dos de la tarde en adelante ${ }^{32}$, amenizando las veladas de su clientela.

Como se ha podido constatar, a partir de estos años los cafés de Zaragoza se extendieron más allá de la calle del Coso, hacia el Sur de la ciudad, donde ya se habían reconstruido la mayor parte de los edificios destruidos por los dos asedios de las tropas francesas. Así, en los años treinta, como indica Isabel Yeste, se trazó la configuración del nuevo Salón de Santa Engracia -a semejanza de los boulevares parisinos-, y se procedió a la remodelación de la céntrica plaza de la Constitución ${ }^{33}$. De este modo, el Ilamado Salón de Santa Engracia vino a sustituir a las ruinas, viejas tapias y huertas de los conventos desamortizados que cubrían buena parte del extremo Sur de la ciudad, por edificios que hablaban de novedad y progreso, muchos de los cuales acogerían en su planta baja, como veremos a continuación, locales comerciales o de congregación y entretenimiento. La burguesía zaragozana trasladó también sus viviendas a esta nueva avenida y se interesó por el embellecimiento y disfrute de ese entorno en el que desarrollaba su vida social.

29. Este café fue establecido en 1835 en la planta baja de un inmueble situado en el Coso, esquina al arco de Cineja. Diario de Zaragoza, Zaragoza, jueves 18 de junio de 1835, "Noticias particulares de Zaragoza", p. 4.

30. En 1840, Joaquín Mairal solicitó licencia municipal para levantar un inmueble en esta zona, con dos plantas. En él instaló una fábrica, en las proximidades del extinguido convento de Santa Engracia. Diario Constitucional de Zaragoza, Zaragoza, domingo 11 de abril de 1841, "Anuncios", p. 4; y A.M.Z., Sección de Policía Urbana, Reedificación de fachadas, Caja 1.735, expediente núm. 311: "D. Joaquín Mayral pide permiso para levantar un tercer piso en el edificio de su antiguo café del Salón de Pignatelli", 1860.

31. Este inmueble constaba en estos momentos de dos plantas en altura: baja, destinada a fábrica y café; y planta superior, con habitaciones para huéspedes.

32. Diario Constitucional de Zaragoza, Zaragoza, domingo 18 de diciembre de 1842, "Anuncios", p. 4.

33. YESTE NAVARRO, I., "Reforma interior y ensanche en la segunda mitad del siglo en Zaragoza: el plano geométrico". Artigrama 19 (2004), p. 429. 


\section{Los años centrales del siglo: evocación de sus cafés}

Los años centrales del siglo XIX se desarrollaron en un marco de convulsiones políticas y de importantes transformaciones socioeconómicas ${ }^{34}$. Esta situación conllevó una paralización de la actividad constructiva, lo que explica que apenas se inaugurasen nuevos cafés en este período, pudiendo destacar entre los pocos que abrieron sus puertas los siguientes: el café del Valenciano (en 1850, en calle de la Lechuga, núm. 2 -hoy calle de los Estébanes-) ${ }^{35}$; el café del Ciprés (en 1854, en calle del Coso, esquina con calle de Santa Catalina) ${ }^{36}$; y el café de González (en 1859, en la antigua calle de Botigas Hondas, núm. 54) ${ }^{37}$.

Asimismo, de los cafés antes citados pocos seguían en activo a causa de las vicisitudes del momento que motivaban los continuos traspasos y cambios de gestión en los locales, aunque establecimientos como el café de la Constancia (calle del Coso, núm. 39, ahora propiedad de Joaquín Mairal y León Pardo) continuaba siendo uno de los de mayor categoría de la ciudad, debido, especialmente, a las piezas musicales que se ofrecían en su jardín para el recreo de los concurrentes mientras degustaban limonada gaseosa, que en aquellos momentos tenía gran aceptación ${ }^{38}$. También, en el mismo local en el que estuvo el café de las Delicias hasta 1847 se estableció temporalmente el café Suizo (bajo la dirección del suizo Lorenzo Matossi) ${ }^{39}$, perteneciente a una compañía propietaria de varios establecimientos similares en distintas ciudades españolas como Bilbao, Madrid, Barcelona, Pamplona, Burgos, Santander, Granada, Huesca ${ }^{40}$ o Haro $^{41}$. En concreto, el café Suizo de Haro es uno de los pocos que quedan en

34. FORCADELL ÁLVAREZ, C., "El nuevo Estado liberal" (capítulo IV), FORCADELL ÁLVAREZ, C. (coord.), Historia Contemporánea de Aragón. Dos siglos cruciales del siglo XIX al XX. Zaragoza, 1993, pp. 73-96.

35. Diario de Zaragoza. Periódico de Avisos, Zaragoza, domingo 24 de febrero de 1850, "Sección Local", p. 3.

36. El Zaragozano. Diario de Avisos, Zaragoza, viernes 23 de junio de 1854, "Parte Local", pp. 2-3.

37. El Diario de Zaragoza, Zaragoza, jueves 16 de junio de 1859, "Sección de Anuncios", p. 4.

38. El Zaragozano. Diario de Avisos, Zaragoza, domingo 19 de junio de 1853, "Parte Local", p. 2.

39. Diario de Zaragoza. Periódico de Avisos, Zaragoza, miércoles 9 de enero de 1850, "Sección Local", p. 3. Por tanto, este café se abrió dos años después del fundado en Madrid con igual denominación por dos suizos: Pedro Franconi y Francisco Matossi.

40. El café Suizo de Huesca (propiedad de los señores Matossi) fue inaugurado el 15 de junio de 1877. Sobre este café y su actividad socio-cultural, véase RAMÓN SALINAS, J., "Los cafés y su oferta cultural en Huesca durante la primera Restauración (1875-1902)". Argensola 122 (2012), pp. 300-306.

41. En este contexto, cabe decir que en otras localidades riojanas, como Logroño o Santo Domingo de la Calzada, también se abrió un café Suizo, que se convirtió en centro de su vida pública. 


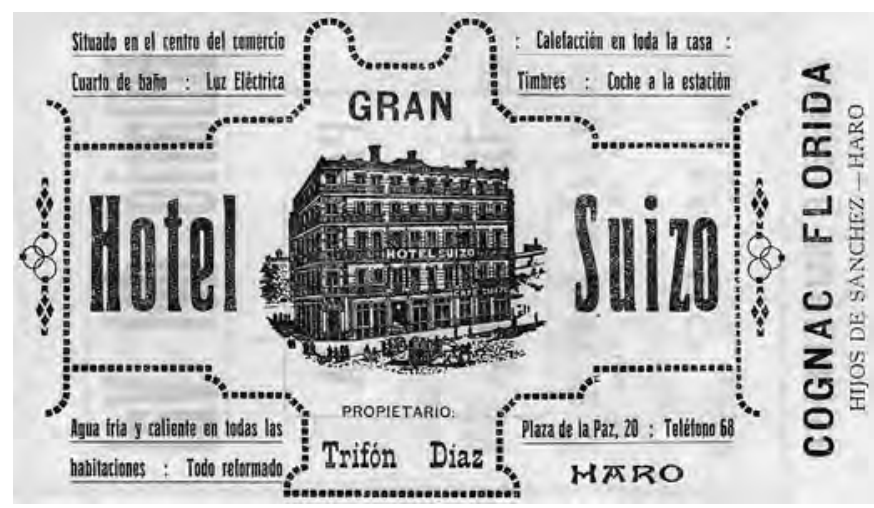

Figura 2. Anuncio publicitario del Hotel y café Suizo de Haro (La Rioja).

la actualidad ${ }^{42}$. Se halla en la planta baja de un edificio ubicado en la céntrica plaza de la Paz, núm. 8, que fue inaugurado en 1865, en un momento de desarrollo económico de esta localidad riojana. Este inmueble constaba de hotel (denominado en origen Europa, y, posteriormente, Hotel Suizo), siendo en aquellos momentos su propietario Trifón Díaz, y de un café (en cuyos bajos -conocidos como "El Sotanillo" - estuvo la cocina y luego una sala de juegos) (Fig. 2). Tras el cierre del hotel, el edificio fue destinado a viviendas, a excepción de su planta baja, que continuó su uso como café, y que aún hoy sigue siendo el lugar preferido de encuentro de los jugadores de cartas.

El café Suizo de Zaragoza era un establecimiento notable por su capacidad y buena distribución, con dos salones delimitados por columnas de hierro, en los que se ejecutaban conciertos musicales que deleitaban a su clientela. Además, en la casa del café Suizo se servían comidas y se daba alojamiento. Este café estuvo situado hasta 1856 en el local del inmueble propiedad de Joaquín Mairal, en paseo de Santa Engracia (cerca de la puerta de Santa Engracia), que, tal y como veremos más adelante, habría de ser ocupado después por el café de la Iberia, y, tras un traslado temporal al circo del Caballo Blanco (calle de los Sitios) ${ }^{43}$, se ubicó definitivamente, en 1858 (y hasta su desaparición en 1916), en la planta baja de la casa núm. 2 del paseo

Además, Logroño contó con otros establecimientos de renombre como el café de Los Dos Leones, que estuvo situado, desde 1886 y hasta su desaparición en 1973, en calle Portales, núm. 68, uno de los ejes urbanos más importantes de esta capital. Heraldo de Aragón, Zaragoza, miércoles 24 de septiembre de 1913, “'El Heraldo' en La Rioja. Logroño y sus fiestas”, pp. 1-4.

42. En este punto quiero expresar mi agradecimiento a los propietarios de este establecimiento por la información aportada, así como a mi familia por su preciada colaboración.

43. RUIZ, F. (edición y notas), Memorias de un zaragozano (1850-1861). Mariano Gracia Albacar. Zaragoza, 2013, p. 91. 


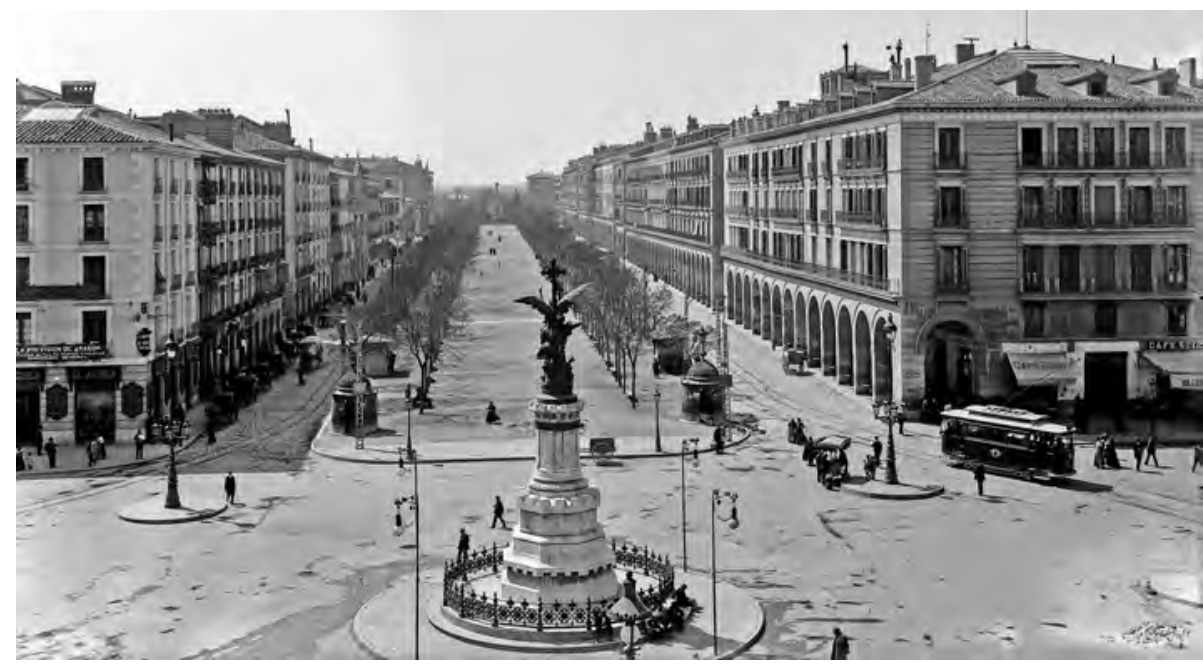

Figura 3. Vista del paseo de la Independencia desde la plaza de la Constitución (a la derecha se aprecia el café Suizo, al inicio de los porches), 1904 (Archivo Histórico Provincial de Zaragoza. Fotografía de Ignacio Coyne, signatura: 000038).

de la Independencia, esquina con plaza de la Constitución (Fig. 3) (4. $^{4}$ En este mismo paseo se emplazó a finales de los cincuenta el café Aragonés, que constaba de dos salones y dos gabinetes elegantemente decorados, en los que los clientes disfrutaban de las veladas de piano mientras saboreaban refrescos y café ${ }^{45}$. De este modo, en estos años comenzaron a conformarse los cafés de apariencia lujosa, que habrían de convertirse en los lugares preferidos de la sociedad burguesa.

La década de los sesenta se inauguró con la visita oficial de Isabel II y de la familia real, en octubre de $1860^{46}$. En esta década se constata un panorama más sosegado a nivel político y social, un mayor desarrollo económico, social y urbano, y un crecimiento de la población zaragozana. Este ambiente se vio pronto alterado con episodios como la Revolución de 1868, que puso fin al reinado de Isabel II y dio paso al período del Sexenio Revolucionario.

En estos años se constata un mayor interés por parte del consistorio municipal por ir atendiendo al ornato público y por acometer, según prescribía la normativa vigente, mejoras urbanas (limpieza de calles, alumbrado público, adoquinado y revoque y pintura de las fachadas de los edificios, sobre todo de

44. El Diario de Zaragoza, Zaragoza, sábado 9 de enero de 1864, "Diario de anuncios", p. 4. 45. El Diario de Zaragoza, Zaragoza, lunes 2 de mayo de 1859, "Sección de anuncios", p. 2. 46. Gaceta de Madrid, núm. 282, lunes 8 de octubre de 1860, "Parte oficial", p. 1. 
cara a la celebración de la Exposición Aragonesa en 186847). También, en época isabelina (que, pese a sus altos y bajos, fue un período de modernización y progreso) se acometió un ambicioso proyecto urbanístico, que modificó considerablemente el antiguo trazado romano de la ciudad, como fue la apertura de la calle de Alfonso I (convertida en lugar de residencia y en espacio de la burguesía ciudadana $)^{48}$, uno de los pocos cambios que experimentó Zaragoza en su trazado en estos momentos.

Esta situación favorable motivó la apertura en esta década de los sesenta de nuevas fondas, como la fonda del Universo (que abrió al público el 1 de marzo de 1862, en calle de Don Jaime I) ${ }^{49}$, y de nuevos cafés, como el café de la Iberia (emplazado en el inmueble propiedad de Joaquín Mairal en paseo de Santa Engracia ${ }^{50}$-luego paseo de la Independencia, núms. 23 y 25-), inaugurado en 186051; el café de Artistas (situado en la antigua calle de la Paja -luego calle de Pignatelli-) abierto en 186152; el café del Duque (sito en la planta baja de la casa núm. 1 de la calle de Espartero, próximo a la antigua puerta del Duque de la Victoria), fundado en junio de $1862^{53}$; el café Univer-

47. Esta exposición se inauguró en Zaragoza el 11 de octubre de 1868.

48. El 13 de agosto de 1858 el Ayuntamiento encargó a los arquitectos municipales Miguel Jeliner y José de Yarza el estudio para la formación de una calle que comenzando en el Coso -a la altura de la calle del Trenque- culminara en la plaza del Pilar. La aprobación de este anteproyecto se concedió por Real Orden de 12 de septiembre de 1861. YESTE NAVARRO, I., "El problema del tráfico en la reforma interior de la ciudad de Zaragoza en época contemporánea". Ciudades 2 (1995), pp. 129-130.

49. El Diario de Zaragoza, Zaragoza, sábado 1 de marzo de 1862, "Diario de anuncios", p. 4.

En julio de 1865 la antigua fonda de las Cuatro Naciones y la del Universo se fusionaron en una sola (bajo el duplicado título de fonda de las Cuatro Naciones y del Universo), quedando al frente de la misma Gaudencio Fortis. El edificio donde se refundieron fue el de la del Universo, en calle de Don Jaime I, núm. 52, y contaba, entre otras dependencias y en su planta baja, con un magnífico café de homónima denominación. El Diario de Zaragoza, Zaragoza, domingo 9 de julio de 1865, "Gacetillas", p. 3.

Por su parte, el inmueble que ocupaba la fonda de las Cuatro Naciones (en Coso, núm. 5) fue destinado a establecimiento litográfico por Francisco Bello (antiguo dependiente de la casa de Peiró). El Diario de Zaragoza, Zaragoza, domingo 3 de diciembre de 1865, "Diario de anuncios", p. 4. En la actualidad, en este espacio se halla instalada la Droga Alfonso.

50. En este local, como hemos indicado anteriormente, estuvo situado el café de las Delicias hasta 1847, año en el que se instaló el café Suizo, que permaneció en este emplazamiento hasta 1856.

51. En 1865 se acometió una reforma interior en este establecimiento, que contaba con un espacioso jardín (cubierto con un bonito emparrado y capaz para unas 180 mesas) en la parte posterior (paseo de la Independencia, núm. 27), en el que se ejecutaban piezas de música por acreditados profesores como Rafael Navarro. El Diario de Zaragoza, Zaragoza, viernes 10 de noviembre de 1865, "Gacetillas", p. 3.

52. El Diario de Zaragoza, Zaragoza, sábado 28 de septiembre de 1861, p. 3.

53. El Diario de Zaragoza, Zaragoza, domingo 15 de junio de 1862, "Diario de anuncios", p. 4. 
so (paseo de la Independencia, núm. 14), que se abrió el 7 de octubre de 186254; el café del Centro (calle de la Torre Nueva, núm. 62), que le siguió en 186455; el café de la Concordia (calle de las Escuelas Pías, núm. 1) ${ }^{56}$, el de la

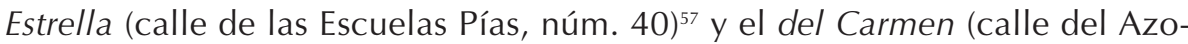
que, núm. 45) ${ }^{58}$, que lo hicieron en 1866; el café abierto por Francisco Hernández con el título de Industrial (calle del Coso, núm. 9), que se inició en $1867^{59}$; el instalado en este mismo año (Coso núm. 87) bajo la denominación de café del Correo ${ }^{60}$; o el café de la Victoria (ubicado junto a la plaza del mismo nombre), establecido por Mariano Onclús en $1869^{61}$. Mención especial entre todos ellos merece el café Universo (denominado más tarde café Universal), que fue fundado en 1862 por los señores González y Marco con dos lujosos y espaciosos salones. Un año después, el 24 de mayo de 1863, se abrió, como dependencia de este mismo café, un salón-jardín en donde el público podía disfrutar de un delicioso ambiente bajo un elegante entoldado y odoríferas plantas ${ }^{62}$.

54. El Diario de Zaragoza, Zaragoza, martes 7 de octubre de 1862, "Diario de anuncios", p. 4.

55. El Diario de Zaragoza, Zaragoza, domingo 17 de enero de 1864, "Diario de anuncios", p. 4.

Este local fue traspasado con sus enseres en diciembre de 1865 y abrió posteriormente sus puertas con la misma denominación. El Diario de Zaragoza, Zaragoza, viernes 8 de diciembre de 1865, "Sección de anuncios", p. 4; y El Diario de Zaragoza, Zaragoza, jueves 24 de diciembre de 1874, "Gacetillas", p. 3.

56. El Diario de Zaragoza, Zaragoza, sábado 17 de febrero de 1866, "Sección de anuncios", p. 4.

Este café se emplazó en el local del antiguo café Ibérico (fundado en 1846). Diario de Zaragoza. Periódico de Avisos, Zaragoza, jueves 11 de junio de 1846, "Sección Local", p. 3.

57. El Diario de Zaragoza, Zaragoza, sábado 9 de junio de 1866, "Sección de anuncios", p. 4.

58. El Diario de Zaragoza, Zaragoza, domingo 23 de diciembre de 1866, "Gacetillas", p. 3.

Este establecimiento cambió de gestión en 1868, pasando a denominarse café de la Independencia. El Diario de Zaragoza, Zaragoza, martes 24 de noviembre de 1868, "Sección de anuncios", p. 4.

59. El Diario de Zaragoza, Zaragoza, domingo 24 de noviembre de 1867, "Gacetillas", p. 3.

Este café tuvo una efímera existencia, debido a que cerró sus puertas el 9 de septiembre de 1868. A.M.Z., Sección de Estadística, Incidencias, Caja 1.305, expediente núm. 3: "Sobre remitir a la Superioridad un estado de tertulias públicas, cafés, villares y tabernas que existieron en Zaragoza en 1868", 1869.

60. El Diario de Zaragoza, Zaragoza, sábado 27 de abril de 1867, "Sección de anuncios", p. 2.

Este establecimiento se cerró poco después y se reabrió en octubre de 1869, cambiando además su denominación por la de café Nacional. El Diario de Zaragoza, Zaragoza, miércoles 6 de octubre de 1869, "Gacetillas", p. 3.

61. El Diario de Zaragoza, Zaragoza, domingo 3 de octubre de 1869, "Gacetillas", p. 3.

62. El Diario de Zaragoza, Zaragoza, domingo 24 de mayo de 1863, "Diario de anuncios", p. 4.

Este establecimiento fue reformado y decorado en 1865. El Diario de Zaragoza, Zaragoza, domingo 12 de noviembre de 1865, "Gacetillas", p. 3. 
Asimismo, en esta década continúan algunos de los cafés ya existentes como el café del Valenciano ${ }^{63}$ o el café Aragonés (posteriormente café Matossi) ${ }^{64}$, y los renombrados y selectos café de la Constancia (calle del Coso, núm. 39, esquina al arco de Cineja) y café Suizo (planta baja de la casa del paseo de la Independencia, núm. 2, esquina con plaza de la Constitución, núm. 3). Por tanto, y como hemos podido comprobar, los nuevos establecimientos seguían agrupándose especialmente en la calle del Coso o en el paseo de la Independencia, dos de los enclaves urbanos más favoritos y concurridos por la sociedad de la época (que también destacaban por su carácter comercial y cultural) ${ }^{65}$ junto con la calle de Don Jaime I, que se conformó en estos momentos como espacio residencial y comercial. Excepcionalmente, se emplazaron en otros lugares no tan céntricos con el fin de atender la demanda de otros sectores poblacionales; así, en 1866, se abrió el café-restaurant de la Victoria en el paseo de Torrero ${ }^{66}$, que presentaba un carácter más variopinto.

Además de estos locales se contaba con otros espacios del mismo tipo ubicados en otros establecimientos o asociaciones que destinaban parte de su extensión para café, como sucedía en el Círculo Artístico e Industrial (en la antigua calle del Trenque -luego calle de Alfonso I, en concreto, su primer tramo desde el Coso-, núm. 1), o aquellos que se instalaron con carácter provisional con motivo de festejos. A este respecto, cabe mencionar que 1862 se levantó temporalmente un Embalat en el paseo de la Independencia, que fue transportado desde la ciudad condal a Zaragoza para las fiestas de Carnaval ${ }^{67}$. El Embalat era una instalación provisional que se componía de varios departamentos, entre ellos, de un salón para baile, de otro para café y de un restaurant. Debido a su éxito, siguió montándose en años sucesivos en el paseo de la Independencia con ocasión de las fiestas del Pilar ${ }^{68}$ o en temporada de verano ${ }^{69}$. Dado que en junio de 1864 se levantó el Salón de Novedades ${ }^{70}$ en el lugar donde se emplazaba el Embalat, éste se ubicó a partir de ese año en la calle del Cinco de Marzo ${ }^{71}$.

63. Hubo otro café con esta misma denominación situado en la plaza del Mercado.

64. El café Aragonés existió hasta 1865, año en el que un nuevo café (el Matossi) se situó en su local. El Diario de Zaragoza, Zaragoza, jueves 2 de marzo de 1865, "Gacetillas", p. 3.

65. La calle del Coso y sus inmediaciones seguían conservando su carácter comercial con establecimientos como las confiterías y reposterías del Buen Gusto, La flor de Almíbar, Casa Lac y El Siglo.

66. El Diario de Zaragoza, Zaragoza, jueves 14 de junio de 1866, "Sección de anuncios", p. 4.

67. El Diario de Zaragoza, Zaragoza, jueves 27 de febrero de 1862, "Novedad", p. 3.

68. El Diario de Zaragoza, Zaragoza, sábado 11 de octubre de 1862, p. 2.

69. El Diario de Zaragoza, Zaragoza, domingo 22 de junio de 1862, "Gacetillas", p. 3.

70. El Diario de Zaragoza, Zaragoza, jueves 23 de junio de 1864, "Gacetillas", p. 3.

71. El Diario de Zaragoza, Zaragoza, jueves 2 de febrero de 1865, p. 3. 
Por tanto, estos cafés fueron espacios de entretenimiento para la sociedad zaragozana, junto con los distintos teatros, salones y circos con los que contaba la ciudad, que han sido objeto de estudio por Amparo Martínez ${ }^{72}$.

\section{Las tres últimas décadas del siglo XIX: los viejos cafés de grandes espejos y mármoles blancos}

La década de los setenta y, especialmente sus primeros años, fueron de mayor moderación (sobre todo si se comparan con la década anterior) a nivel de acometida de obras públicas así como de desarrollo de nuevas actividades mercantiles, a causa de los enfrentamientos bélicos derivados de la tercera guerra carlista. Sin embargo, con la instauración de la restauración monárquica con Alfonso XII, en 1875, se inició un período de importantes transformaciones sociales y económicas. De hecho, y dentro del tema que nos ocupa, fue la Edad de Oro del café en nuestro país, sobre todo coincidiendo con la de los años de la Restauración y de la regencia de María Cristina, durante el último tercio del siglo XIX y los primeros años del siglo $\mathrm{XX}^{73}$, aunque su relevancia continuó hasta los años cincuenta.

En esta década muchos de los establecimientos antes citados se traspasaron o cerraron, aunque siguieron manteniéndose algunos, como el café del Duque, el café del Centro ${ }^{74}$, el café de la Concordia, el café de la Estrella ${ }^{75}$, el café de la Independencia (antiguo del Carmen) y el café del Correo, así como los antiguos y prestigiosos café de la Constancia ${ }^{76}$, café Suizo, café de la Iberia, café Uni-

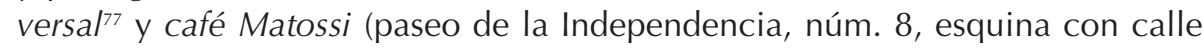

72. Los teatros, salones y circos que se abrieron en este período han sido estudiados por Amparo Martínez en esta publicación: MARTíNEZ HERRANZ, A., La arquitectura teatral en Zaragoza..., pp. 144-201.

73. BONET CORREA, A., Los cafés históricos, p. 38.

74. El dueño de este café también era el encargado en estos años del servicio del restaurante de la torre de Bruil (en la actualidad parque Bruil), denominada en la época Quinta de Bruil. El Diario de Zaragoza, Zaragoza, jueves 15 de julio de 1875, "Gacetillas", p. 3.

75. Este café emplazado en calle de las Escuelas Pías, núm. 17, fue traspasado en octubre de 1871 y reabrió sus puertas poco después bajo la dirección de un nuevo propietario. El Diario de Zaragoza, Zaragoza, martes 3 de octubre de 1871, "Sección de anuncios", p. 4.

76. Este establecimiento, propiedad de los señores Pardo y compañía, fue renovado en su decorado a principios de agosto de 1877, abriéndose a finales de este mes el salón con acceso desde calle del Coso. Por su parte, el otro salón con el que contaba, ubicado en calle de los Mártires, sufrió igual reforma. El Diario de Zaragoza, Zaragoza, miércoles 22 de agosto de 1877, "Gacetillas", p. 3.

77. El café Universal, propiedad de José Fernández y González, pasó en 1870 a ser gestionado por Julio Zoppetti, que se hallaba al frente del café de Europa. Con este cambio de titularidad, el espacioso salón del Universal fue nuevamente decorado. El Diario de Zaragoza, Zaragoza, sábado 24 de septiembre de 1870, "Gacetillas", p. 3. 
del Cinco de Marzo; muy próximo al café Suizo ${ }^{78}$, que continuaban amenizando las veladas de los clientes con bailes y conciertos musicales (como el ofrecido las noches del 3 y 4 de agosto de 1871 por la reputada arpista del teatro Real señorita Medina en el salón-jardín del café de la Iberia $)^{79}$. Además, seguían abiertos los cafés instalados en las fondas de Europa, de las Cuatro Naciones y del Universo, que contaban igualmente con una abundante clientela. En este contexto, cabe señalar que, en 1871, el café de Europa fue reformado y sus dos salones decorados con pinturas ejecutadas por el pintor Saleta ${ }^{80}$.

Asimismo, en esta década tuvo lugar la apertura de nuevos centros de esparcimiento y encuentro social como el café del Siglo (paseo de la Independencia), abierto en 187081; el café del Comercio (calle de Alfonso I, esquina con calle de Contamina), que fue inaugurado el 9 de abril de 187182; el café Oriental (plaza de la Constitución, núm. 6), en $1872^{83}$; el café de París (situado en la planta baja del edificio ocupado por el Casino Principal -con sede en la planta noble del palacio de Sástago-, en el Coso, núm. 56), que se abrió al público el lunes 2 de octubre de $1876^{84}$. Poco después, en el jardín emplazado en la parte posterior de este último establecimiento, se instaló un Skating-Rink ${ }^{85}$, es decir, una pista de patinaje sobre hielo que se convirtió en pasatiempo de muchos zaragozanos aunque por poco tiempo, dado que se incendió tres años después (el domingo 14 de

A partir del 12 de agosto de 1873 este local destinó parte del mismo a pastelería (centrándose a partir de este momento en este género). El Diario de Zaragoza, Zaragoza, sábado 11 de agosto de 1873, "Sección de anuncios", p. 4.

78. En 1873 los dueños (Matossi, Monigatti y compañía) de este café le dotaron de un magnífico jardín (en el que se dispusieron mesas de mármol entre farolas y un frondoso arbolado), con entrada directa por la calle del Cinco de Marzo. Este salón-jardín se habilitaba únicamente en temporada de verano y en el período de celebración de las fiestas del Pilar, y en él se ofrecían conciertos musicales. El Diario de Zaragoza, Zaragoza, lunes 16 de junio de 1873, "Gacetillas", p. 3.

79. El Diario de Zaragoza, Zaragoza, sábado 3 de agosto de 1871, "Gacetillas", p. 3.

80. El Diario de Zaragoza, Zaragoza, martes 11 de abril de 1871, "Gacetillas", p. 3.

En 1877 este café fue nuevamente decorado. El Diario de Zaragoza, Zaragoza, lunes 10 de septiembre de 1877, "Gacetillas", p. 3.

81. El Diario de Zaragoza, Zaragoza, domingo 9 de enero de 1870, "Sección de anuncios", p. 4.

82. El Diario de Zaragoza, Zaragoza, domingo 9 de abril de 1871, "Sección de anuncios", p. 4.

83. El viernes 21 de junio de 1872 se inauguró una elegante horchatería en la plaza de la Constitución, núm. 6. Tres meses después, ese local, además de a horchatería, fue destinado a café. El Diario de Zaragoza, Zaragoza, domingo 23 de junio de 1872, "Gacetillas", p. 3.

84. El Diario de Zaragoza, Zaragoza, martes 3 de octubre de 1876, "Gacetillas", p. 3.

Este café sufrió una reforma en 1880, así la valla que dividía el salón principal fue eliminada y los billares se instalaron en sus espaciosos salones interiores. El Diario de Zaragoza, Zaragoza, viernes 14 de diciembre de 1880, "Gacetillas", p. 3.

85. El Diario de Zaragoza, Zaragoza, sábado 30 de septiembre de 1876, "Gacetillas", p. 3. 
diciembre de 1879) ${ }^{86}$; o el café de España (paseo de la Independencia, núm. 26), en $1878^{87}$. Como puede constatarse, sorprende la denominación de alguno de estos cafés, que pretenden evocar por su modernidad los cafés parisinos y por sus decorados el exotismo de lejanas culturas en boga en aquellos momentos ${ }^{88}$.

Como puede comprobarse nuevamente, las calles del Coso, de Alfonso I y de Don Jaime, así como el paseo de Independencia y la plaza de la Constitución, conformaban una zona urbana en la que se concentraban los más acreditados y concurridos cafés de la capital aragonesa (a su vez, próximos entre sí, como para permitir el paso de uno a otro sin tener que caminar demasiado), así como otros famosos establecimientos comerciales o dedicados al ocio y al espectáculo. También, la vida cultural y social zaragozana se amenizaba en aquellos momentos con funciones taurinas, con sesiones musicales y literarias (desarrolladas en el Casino Mercantil o en el Círculo de San Luis), con representaciones teatrales (como las celebradas en el teatro Principal, teatro de Novedades, teatro Lope de Vega o, desde 1878, en el teatro de Pignatelli ${ }^{89}$; espacios que estaban en funcionamiento en esta área y que acogían, por lo general, en sus instalaciones un café-restaurant y un salón de descanso ${ }^{90}$ ), o con conciertos ofrecidos en cafés cantantes, como el del Cinco de Marzo ${ }^{91}$. Estos

86. El Diario de Zaragoza, Zaragoza, lunes 15 de diciembre de 1879, "Gacetillas", p. 2.

87. El Diario de Zaragoza, Zaragoza, miércoles 3 de julio de 1878, "Gacetillas", p. 3. Este café tuvo una corta existencia.

88. Así, por ejemplo, el café del Comercio fue lujosamente decorado con cristales, que fueron colocados en la parte baja de cada una de las hojas de la puerta de entrada, con medallones en colores que, sobre un fondo blanco mate, presentaban animados paisajes, delicados grupos de flores y delineadas figuras. Esta decoración fue acometida por el artista Pedro Pascual. El Diario de Zaragoza, miércoles 12 de abril de 1871, "Gacetillas", p. 3.

89. Este teatro, proyectado por el arquitecto Félix Navarro, se emplazó en 1878 en el paseo de la Independencia, núm. 29. El Diario de Zaragoza, Zaragoza, sábado 10 de agosto de 1878, "Gacetillas", p. 3. Fue cerrado en 1914 y demolido un año después.

90. Así, el teatro de Pignatelli contaba con un café adyacente (levantado en su jardín) que confrontaba con la calle de Don Juan Bruil y era gestionado por Enrique Zoppetti. Se trataba de una sencilla construcción, de una sola planta, que, en 1885, fue elevada en un piso conforme al proyecto formulado en abril de ese año por el arquitecto Félix Navarro. A.M.Z., Sección de Policía Urbana, Licencias para edificar, Caja 1.539, expediente núm. 497: “D. Enrique Zoppetti pide permiso para levantar un piso sobre el café del Teatro de Pignatelli que confronta con la calle de Bruil", 1885.

91. Este café cantante se inauguró en diciembre de 1870 en calle del Cinco de Marzo. Dos años después fue renovado y abrió nuevamente sus puertas el 8 de septiembre de 1872 bajo la denominación de café de España. El Diario de Zaragoza, Zaragoza, jueves 15 de diciembre de 1870, "Gacetillas", p. 3; y El Diario de Zaragoza, Zaragoza, miércoles 4 de septiembre de 1872, "Gacetillas", p. 3.

En septiembre de 1874, este café pasó a manos de una nueva empresa, que introdujo algunas mejoras y una nueva denominación: La Infantil. El Diario de Zaragoza, Zaragoza, miércoles 23 de septiembre de 1874, "Gacetillas", p. 3. 
puntos de encuentro reflejan la creciente actividad cultural y recreativa que se vivía en Zaragoza, al igual que en otras ciudades como Madrid o Barcelona.

En la década de los ochenta seguían amenizando la vida cultural y social zaragozana los cafés del Duque, de la Estrella, de la Independencia ${ }^{92}$, del Siglo, del Comercio y Orienta/93, así como ya los acreditados café de la Constancia (que en 1881 cambió de gestión, pasando a denominarse café de Londres ${ }^{94}$ ), café Suizo, café de la Iberia, café Universal, café Matossi y café de París. A éstos cabe sumar, los instalados en los hoteles de Europa y de las Cuatro Naciones y del Universo ${ }^{95}$.

La mayoría de estos antiguos cafés, igual que otros locales comerciales y centros de ocio, renovaron con bastante frecuencia su decoración y mejoraron el confort de sus dependencias y servicio en función de las modas y de los avances del momento. De este modo, y en pleno auge de la pintura decorativa, el café de la Iberia practicó obras en 1883 en su decorado, especialmente, en el del salón (en el que unos cuadros, la mayoría debidos al pintor Urrutia, cubrían sus paredes y techo), se colocaron nuevos aparatos de luz y se renovó el tapizado de sus divanes y sillas ${ }^{96}$; o el café de París fue decorado en 1884 por el pintor y escenógrafo madrileño Limones $^{97}$.

Además, en esta década de los ochenta, se mantuvo y refuerza el desarrollo de los cafés (como en otras ciudades españolas, tal es el caso del café de España en Valencia, inaugurado en 1889), que se había iniciado a partir de media-

92. Este café estuvo abierto hasta julio de 1883. El Diario de Zaragoza, Zaragoza, sábado 7 de julio de 1883, "Anuncios", p. 4.

93. Este café situado en la planta baja de la casa de la plaza de la Constitución, núm. 6, cambió de gestión y en 1903 fue habilitado para acoger un nuevo café con el título de café de la Perla. A.M.Z., Sección de Fomento, Licencias de obras, Caja 1.243, expediente núm. 1.362: "D. Vicente Parra pidiendo autorización para practicar varias obras en la planta baja de la casa no 6 de la plaza de la Constitución y colocación de una marquesina", 1903.

El local de este café sería ocupado posteriormente por otro establecimiento de homónimo destino, y, en concreto, por el café Salduba.

94. El Diario de Zaragoza, Zaragoza, miércoles 15 de junio de 1881, "Gacetillas", p. 3.

En septiembre de 1885, Juan Olano como propietario de este establecimiento (que ocupaba hasta ese momento el amplio local de la planta baja del edificio situado en calle del Coso, núm. 39, esquina con calle de los Mártires, núm. 1) redujo el espacio destinado a este café, quedando tan sólo a éste una puerta de entrada por la calle de los Mártires, núm. 1. También cambió la farola que existía en su puerta de entrada por otra de mayores dimensiones y potencia luminosa. A.M.Z., Sección de Policía Urbana, Mercado y ferial, Caja 1.547, expediente núm. 1.061: "D. Juan Olano pide autorización para cambiar la farola que hoy existe en la puerta del café de Londres situada ésta en la calle de Cinegio, por otra de mayores dimensiones y más luminosa", 1886.

95. En 1881 se anuncia, en la prensa local, como Hotel de las Cuatro Naciones y del Universo, siendo su gestor Fortis. El Diario de Zaragoza, Zaragoza, martes 5 de julio de 1881, "Sección de anuncios", p. 4.

96. El Diario de Zaragoza, Zaragoza, sábado 6 de octubre de 1883, "Gacetillas", p. 2.

97. El Diario de Zaragoza, Zaragoza, lunes 7 de julio de 1884, "Anuncios", p. 4. 
dos del siglo, con la apertura de grandes y suntuosos cafés como el café de Ambos Mundos, inaugurado el 3 de octubre de 1881; o el café Gambrinus, abierto el 28 de mayo de 1889. Estos dos cafés inauguran un nuevo tipo de establecimiento: espacioso, confortable y ostentoso.

En cuanto al primero citado (situado en la planta baja de un inmueble recién construido, propiedad de José Sánchez y Manuel Puy ${ }^{98}$, al final de los porches del paseo de la Independencia, núms. 30-32; y ocupando, en origen, toda una manzana comprendida entre las actuales calles Marqués de Casa Jiménez y Albareda), hay que decir que de la dirección de sus obras se encargó el maestro de obras Antonio Miranda y de la pintura y dorado el artista Alejo Pescador $^{99}$. El periódico El Diario de Zaragoza describía este café el día de su apertura con las siguientes palabras:

[...] El salón, que ocupa toda la planta baja del edificio, tiene una longitud de $38 \mathrm{~m}$ por 21 de ancho y 7 de altura. Además hay un gabinete en cada uno de los costados. Componen en ancho tres tramadas: las dos primeras se hallan debajo del edificio y forman la mitad del salón, están sostenidas por diez y ocho columnas de hierro en dos líneas, la otra mitad está cubierta con solo el tejado por corresponder al patio de luces del edificio, por cuyo motivo han sido innecesarias las columnas, obteniéndose la mitad del salón completamente despejado.

Doce arcos de los porches corresponden al salón y gabinetes, y dos puertas dan entrada al primero, si bien hay dispuestas otras dos, diez huecos con iguales dimensiones a las puertas existen en el salón en la fachada posterior y cuatro en cada uno de los lados dando entrada a los gabinetes, salón de billares y demás departamentos.

Doscientas ocho mesas de mármol se han colocado entre los gabinetes y las cuatro naves o divisiones en que se han distribuido longitudinalmente el salón.

98. Manuel Puy y José Sánchez, como propietarios de los seis solares que comprendía la manzana señalada con la letra A de los terrenos procedentes de la Exposición Aragonesa y adyacentes, solicitaron licencia a la municipalidad el 12 de diciembre de 1878 para construir un edificio de nueva planta, con arreglo al plano de fachada formulado por Antonio Miranda, sobre los tres solares que de la indicada manzana lindaban con la calle de la Independencia. Pocos días después el consistorio municipal les otorgó la licencia requerida y este edificio fue terminado en 1881. A.M.Z., Sección de Policía Urbana, Licencias para edificar, Caja 1.807, expediente núm. 1.180: “D. Manuel Puy por sí y en nombre de D. José Sánchez pidiendo licencia para construir un edificio en los solares de la manzana letra A de la Exposición Aragonesa conforme al plano que presenta", 1878.

99. Alejo Pescador, como otros jóvenes artistas zaragozanos del momento, se relacionó con la escenografía y con la pintura decorativa (de teatros, cafés, etc.). A este respecto, véase GARCÍA GUATAS, M., "Una generación de pintores partida por el medio siglo". Artigrama 22 (2007), p. 643. 
La pintura y dorado de este grandioso café es obra de Alejo Pescador, artista conocido en esta capital por otras obras de relevante mérito. Cuatro magníficas figuras que representan Asia, África, Europa y América se destacan en primer término; ellas y el techo de estilo pompeyano y todos los demás adornos y grupos de este salón corresponden por su mérito al crédito que como pintor hace tiempo que disfruta con justo motivo, el sr. Pescador $[\ldots]^{100}$.

Como puede deducirse de este texto, el café de Ambos Mundos destacaba por su luminosidad (dado que contaba con amplias ventanas que permitían una transición fluida entre la vida exterior e interior de la ciudad) y notables dimensiones (de hecho, estaba considerado como uno de los más grandes de Europa y el más amplio de la capital aragonesa seguido por el café de la lberia y por el café Suizo), conseguidas por el uso del hierro en su construcción, siguiendo así las tendencias estéticas dominantes. Asimismo, fue decorado en su interior -para acoger con más complacencia a la burguesía zaragozana- con escenas relacionadas con los continentes, dentro del gusto de la época por los temas alegóricos, y con elementos decorativos de raigambre clásica. Contaba además con un restaurant y con un jardín, donde en las noches de verano se desarrollaban veladas musicales que enriquecían el programa de conciertos diarios que tanta concurrencia llevaban a este establecimiento.

En este café se fueron acometiendo mejoras y reformas a lo largo de su existencia. De hecho, en 1885, se inauguró el alumbrado eléctrico, sustituyendo a la luz de gas ${ }^{101} ;$ y, en 1889, fue completamente reformado (decoración general del salón -en estilo renacimiento- y artesonado del techo, colocación de espejos, etc. $)^{102}$, teniendo en cuenta las tendencias historicistas de la época (Fig. 4). Del proyecto general y de la dirección decorativa del salón se ocupó el arquitecto zaragozano Julio Bravo ${ }^{103}$. De hecho, Ilegó a convertirse en uno de los más importantes de la ciudad y en un referente en nuestro país. Sin embargo, su renombre y prestigio no le salvaron de su cierre el 2 de septiembre de $1955^{104}$,

100. El Diario de Zaragoza, Zaragoza, lunes 3 de octubre de 1881, "Gacetillas", p. 3.

101. El Diario de Zaragoza, Zaragoza, lunes 20 de abril de 1885, "Gacetillas", p. 3.

102. El Diario de Zaragoza, Zaragoza, martes 18 de junio de 1889, "Crónica del día”, p. 2; y El Diario de Zaragoza, Zaragoza, domingo 15 de septiembre de 1889, "Crónica del día", p. 2.

103. Entre las varias obras que se ejecutaron hay que mencionar la construcción de nueva planta de un pabellón de cocinas, situado en el antiguo jardín. Esta como todas las obras restantes fueron dirigidas por Antonio Miranda y Fondevila. Entre los artistas que cooperaron en las obras de reforma y decoración de este café cabe destacar: pintores Nazario Benedí y Valentín Maiz; tallistas, señores Gargallo hermanos y Manuel Arpal; espejos y cristalería, Basilio Paraíso; grabado de cristales, León Quintana; y tapicería y ebanistería, Manuel y Raimundo Muñoz. El Diario de Zaragoza, Zaragoza, miércoles 25 de septiembre de 1889, "El café de Ambos Mundos", pp. 1-2.

104. Heraldo de Aragón, Zaragoza, viernes 2 de septiembre de 1955, "Otro café desaparece. El cierre de Ambos Mundos", p. 4. 


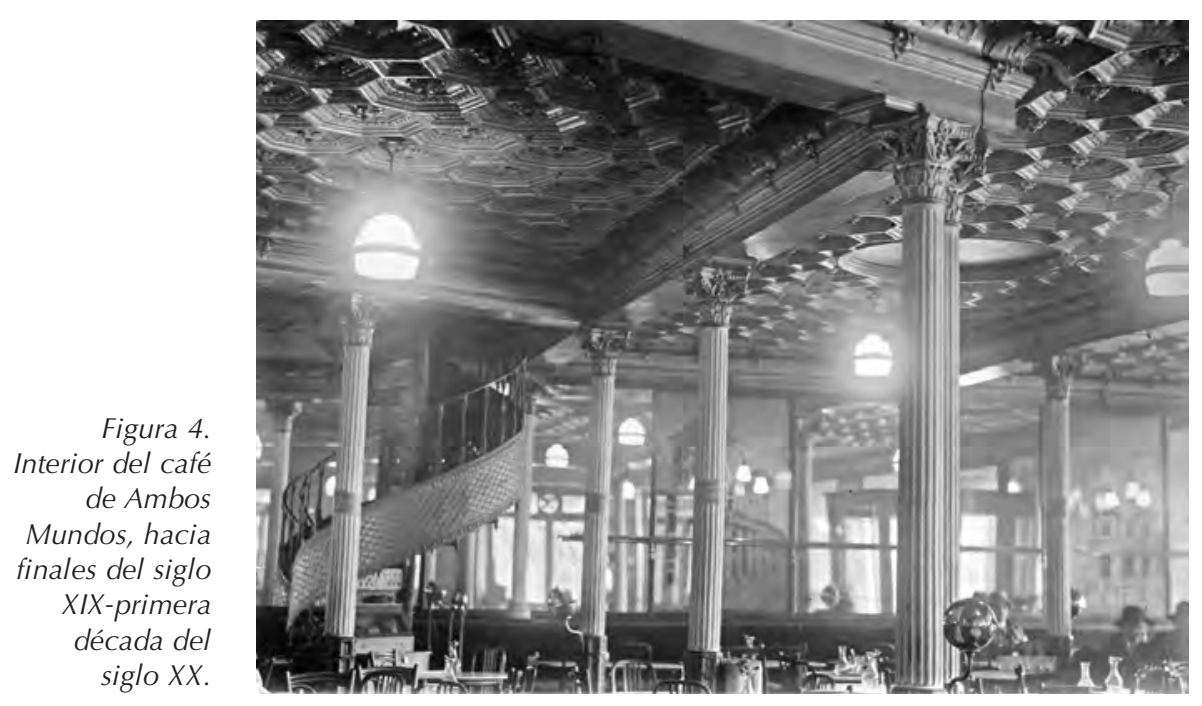

aunque la imagen de sus divanes de terciopelo y grandes espejos siga estando en el recuerdo de generaciones pasadas.

Tras la fundación del café de Ambos Mundos (1881) hubo que esperar unos años para que la ciudad acogiera otro gran establecimiento: el café Gambrinus (el rey germánico inventor de la cerveza), abierto por Pablo Gil el 28 de mayo de 1889, en la planta baja de la casa de la plaza de la Constitución, núm. 1 (en un local anteriormente ocupado por el café Español y luego por una horchatería, y junto al edificio de la Diputación Provincial) (Fig. 5), al estilo de las modernas brasseries de París (Fig. 6) ${ }^{105}$. Por tanto, su apertura tuvo lugar un año antes de la del célebre café Gambrinus de Nápoles, y era anunciada como punto de encuentro de la sociedad comme il faut y de los aficionados al buen café y a la buena cerveza, y en él se dio a conocer al público la soda inglesa ${ }^{106}$. Este acreditado café, en el que se daban cita numerosos con-

105. Pablo Gil hizo colocar en este establecimiento en 1889 una portada de sencillo diseño (conformada en madera por pilastras a ambos lados de las puertas y por espejos), pero hasta abril de 1892 (y tras reiteradas peticiones por parte del consistorio municipal y con advertencia de retirarle el permiso para poder colocar veladores durante la estación veraniega en caso de no proceder a lo solicitado) no presentó plano o croquis de la misma. Con fecha de 12 de abril de 1892, y tras el informe favorable del arquitecto municipal, el Ayuntamiento autorizó el mantenimiento de la portada. A.M.Z., Sección de Policía Urbana, Policía comercial e industrial, Caja 309, expediente núm. 507: "D. Pablo Gil, solicita permiso para sacar a la acera de su establecimiento de cervezas y refrescos de la plaza de la Constitución $n^{\circ}$ 1, seis mesas o veladores con sillas", 1892. Referencia figura: 1-9-7_0000507-1892_0002.

106. El Diario de Zaragoza, Zaragoza, miércoles 29 de mayo de 1889, "Crónica del día", p. 2. 


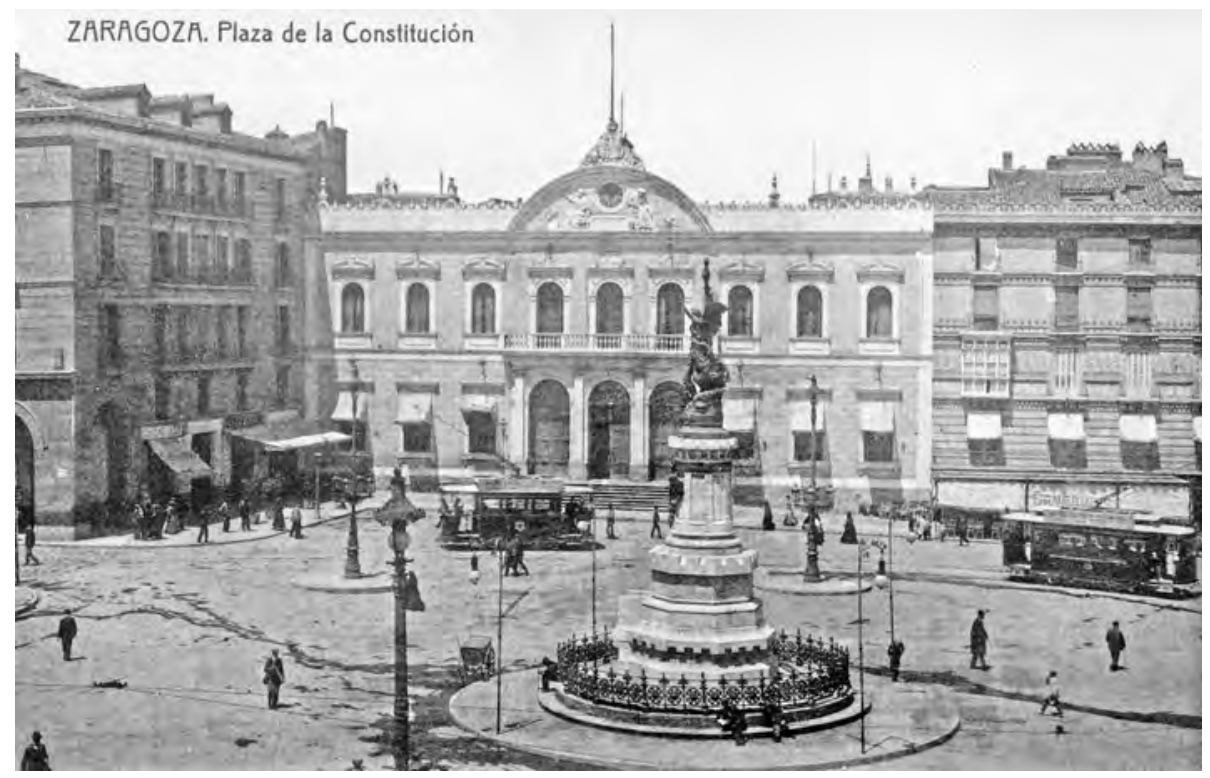

Figura 5. Aspecto de la plaza de la Constitución (hoy de España) y el café Gambrinus (abajo a la derecha), hacia la década de los diez del siglo XX (Archivo Municipal de Zaragoza, signatura: 00131).

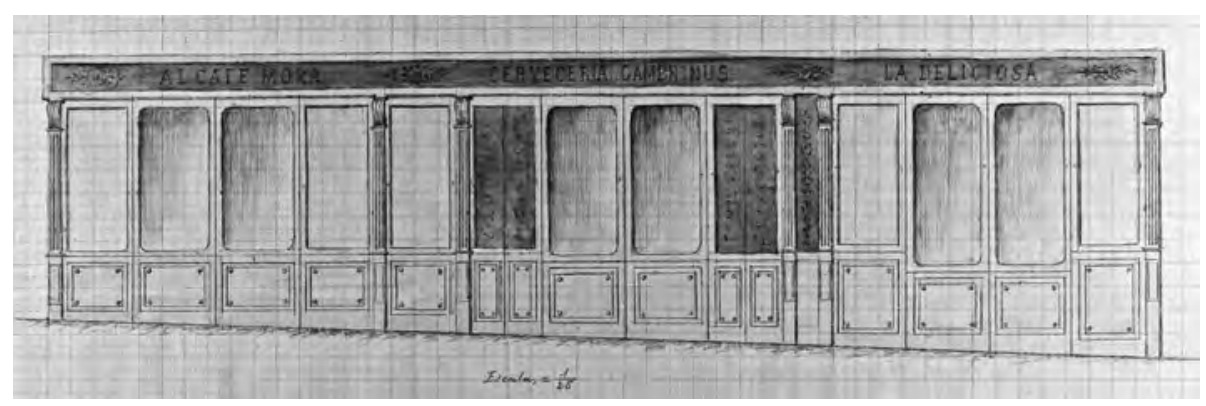

Figura 6. Diseño de la portada del café Gambrinus (plaza de la Constitución, núm. 1), 1892 (Archivo Municipal de Zaragoza). 
tertulios, fue clausurado en $1968^{107}$. Con su cierre terminaron sus fieles y disertas tertulias como las presentadas a principios de siglo por Juan Gimeno Rodrigo (y a las que concurrían, entre otros, escritores y eruditos como Jerónimo Vicén, Hilarión Gimeno y Fernández-Vizarra, José Galiay y José García Mercadal), y la ciudad vio desaparecer uno de sus últimos cafés tradicionales.

Estos cafés además de lugares de ocio, entretenimiento y reunión social, en los que se daban cita diferentes clases de público, eran también, en la mayoría de las ocasiones, espacios para el intercambio de ideas sobre política. Así, en el café de Europa se reunían literatos, periodistas y otras personalidades destacadas del mundo de la política y de la cultura. Por él pasaron ilustres personajes del teatro como María Guerrero (que tomaba allí café cuando actuaba en el teatro Principal) y Jacinto Benavente (quien, cuando vino a Zaragoza para el estreno de su primera obra, solía pasar largos ratos jugando al ajedrez); políticos como Segismundo Moret ${ }^{108}$ o José Canalejas (quienes disfrutaban veladas hablando con sus correligionarios) ${ }^{109}$, o aficionados taurinos (que se congregaban en torno a los diestros que toreaban los días de las corridas del Pilar) ${ }^{110}$. Por su parte, el café Suizo tenía un carácter más popular y era el local favorito de toreros y aficionados a la tauromaquia y reunía a los admiradores de Bruno Solano en sus pláticas diarias; el café de la Iberia acogió hombres ilustres como Santiago Ramón y Cajal, quien acudía asiduamente, durante su residencia en Zaragoza, a jugar partidas de ajedrez ${ }^{111}$; o el café Matossi era generalmente frecuentado por escultores y pintores $^{112}$.

Como puede comprobarse, la mayoría de los cafés citados se emplazaban, como en otras ciudades, en pleno centro urbano, que seguía conservando e incentivando su carácter comercial, cultural y de ocio. Sin embargo, alguno se alejó de esta zona para atender otros puntos de la ciudad (menos concurridos), como el café de Pignatelli, que se situó en calle de Pignatelli, núms.

107. POZA, G., "Para todos cafée", Hoja del Lunes, Zaragoza, lunes 9 de diciembre de 1968, p. 24; La Vanguardia española, miércoles 11 de diciembre de 1968, "Zaragoza: Ha cerrado 'Gambrinus', el último café tradicional", p. 11.

Este local pertenece actualmente a la Diputación Provincial de Zaragoza, y acoge una cafetería con esta misma denominación.

108. Segismundo Moret estuvo en varias ocasiones en Zaragoza. Así, como ministro de Fomento realizó una estancia en esta ciudad a mediados de octubre de 1893. El Diario de Zaragoza, Zaragoza, martes 17 de octubre de 1893, "Crónica del día", p. 3.

109. ARAIZ, A., "Evocación de los viejos cafés de grandes espejos y mármoles blancos", Amanecer, Zaragoza, domingo 2 de junio de 1946, p. 5.

110. SUÁREZ, S., "Cincuenta y dos años a pie de la cafetería", Amanecer, Zaragoza, jueves 18 de julio de 1946, p. 11.

111. RAMÓN Y CAJAL, S., Obras selectas. Madrid, 2000, p. 276.

112. BLASCO, J., "Reportajes retrospectivos", Hoja del lunes, Zaragoza, 21 de enero de 1946, p. 7. 
23 y 25 , en septiembre de $1882^{113}$; o el café Colón, en la calle de Antonio Pérez, núm. $2^{114}$.

Asimismo, como en años anteriores, el ocio zaragozano se completaba con las veladas ofrecidas por cafés cantantes (como el café Aragonés ${ }^{115}$ y el café del Buen Retiro $\left.{ }^{116}\right)$, centros recreativos (como el círculo Goya) ${ }^{117}$, teatros o sociedades de baile.

Esta década de los ochenta se cierra con la visita a la ciudad de la reina regente María Cristina y su hijo Alfonso XIII, a mediados del mes de mayo de $1888^{118}$, con motivo de la cual se desarrollaron numerosos festejos en su honor.

A pesar de la crisis imperante durante la etapa anterior y del desarrollo de las campañas militares de Cuba y Filipinas, los primeros síntomas de recuperación se aprecian en los años finales del siglo XIX, cuando comienzan a percibirse cambios sustanciales en el urbanismo zaragozano (que culminarían en la redacción de un plan de ensanche a comienzos del nuevo siglo ${ }^{119}$ ) y un crecimiento del tejido industrial, entre otros progresos. En la última década del siglo continúan abiertos antiguos cafés como el del Duque ${ }^{120}$, el de la Estrella (que en 1892 pasó a denominarse café Oriental) ${ }^{121}$ o el del Comercio, y renombrados cafés como el Suizo, de la Iberia ${ }^{122}$, Londres, Matossi (que en 1899 pasó a denominarse café de E. Flores) ${ }^{123}$, París

113. En septiembre de 1882 el antiguo café de Peña, situado en estos momentos en calle del Coso esquina con la de la Audiencia, se trasladó a calle de Pignatelli, núms. 23 y 25, con la denominación de café de Pignatelli. El Diario de Zaragoza, Zaragoza, domingo 24 de septiembre de 1882, "Anuncios", p. 2.

En 1894, su propietario Julián Calvo trasladó este establecimiento al número 36 de esta misma calle, manteniendo su denominación de café de Pignatelli. El Diario de Zaragoza, Zaragoza, domingo 24 de junio de 1894, "Crónica del día", p. 3.

114. El Diario de Zaragoza, Zaragoza, sábado 25 de junio de 1892, "Crónica del día”, p. 2.

115. Este establecimiento se creó en 1879 en calle de Cerdán. El Diario de Zaragoza, Zaragoza, miércoles 12 de marzo de 1879, p. 3.

116. Este local se abrió el 20 de junio de 1880 en el salón de Pignatelli. El Diario de Zaragoza, Zaragoza, domingo 20 de junio de 1880, "Sección de anuncios", p. 2.

117. El Diario de Zaragoza, Zaragoza, sábado 20 de abril de 1889, "Crónica del día", p. 2.

118. El Diario de Zaragoza, Zaragoza, sábado 12 de mayo de 1888, "Crónica del día", p. 2.

119. En este contexto, hay que mencionar la actuación del arquitecto municipal Ricardo Magdalena como urbanista y su anteproyecto de ensanche de la ciudad, que ha sido analizado por HERNÁNDEZ MARTíNEZ, A., Ricardo Magdalena. Arquitecto municipal de Zaragoza (1876-1910). Zaragoza, 2012, pp. 150-151.

120. El local ocupado por este café fue destinado en la década de los veinte del siglo pasado a establecimiento de vinos.

121. El Diario de Zaragoza, Zaragoza, domingo 12 de junio de 1892, "Anuncios", p. 4.

122. En enero de 1899, bajo el título de "La Familiar", se constituyó en el gran salón del jardín de la Iberia una sociedad recreativa. Diario de Zaragoza, Zaragoza, viernes 6 de enero de 1899, "Zaragoza", p. 2.

123. Este café toma su nombre de Evaristo Flores, que era hijo del conocido propietario del café Matossi. Heraldo de Aragón, Zaragoza, viernes 3 de noviembre de 1899, "Noticias", p. 1. 
(que en enero de $1910^{124}$, tras ser reformado, abriría sus puertas con la denominación de Nuevo Café de París ${ }^{125}$, sobreviviendo únicamente diez años más $\left.{ }^{126}\right)$, de Ambos Mundos o Gambrinus, que estaban situados en los puntos más céntricos de la ciudad. Asimismo, seguían funcionando los cafés instalados en los hoteles de Europa y de las Cuatro Naciones y del Universo ${ }^{127}$, así como los de más reciente inauguración como el de Pignatelli o de Colón.

En este contexto, cabe mencionar que a finales del año 1889 el café de la Iberia (situado en el paseo de la Independencia, núms. 23 y 25) tuvo que cerrar sus puertas ante la declaración en quiebra de sus propietarios ${ }^{128}$ y fue puesto en arriendo en enero de $1890^{129}$, siendo ocupado, hasta 1892, por el Club Velocipedista $^{130}$. Sin embargo, a finales de ese año, Manuel Pardo solicitó autorización al consistorio municipal para ejecutar en la planta baja de las casas de su propiedad núms. 23 y 25 del paseo de la Independencia una serie de reformas (bajo la dirección del arquitecto Julio Bravo) ${ }^{131}$ con el fin de establecer nueva-

124. Heraldo de Aragón, Zaragoza, miércoles 12 de enero de 1910, "Gran inauguración del café nuevo de París", p. 1.

125. A.M.Z, Sección de Fomento, Licencias para edificar, Caja 1.065, expediente núm. 1.020: "Pedro Ferrer. Colocar marquesina en el Café de París", 1910.

Para esta ocasión, la portada de este establecimiento fue reformada en estilo modernista. Sobre esta obra, véase POBLADOR MUGA, M. ․ P., "La obra modernista del arquitecto tarraconense Ramón Salas Ricomá (1848-1926) en Zaragoza". Artigrama 21 (2006), pp. 535-540.

126. Heraldo de Aragón, Zaragoza, jueves 5 de febrero de 1920, "Noticias", p. 4.

127. En 1890 este hotel fue reformado bajo la dirección del arquitecto Fernando de Yarza. Su planta baja, que estaba ocupaba en esos momentos por el café, fue destinada a restaurant. El Diario de Zaragoza, Zaragoza, miércoles 23 de septiembre de 1890, "El gran Hotel del Universo", p. 2.

128. A.M.Z., Sección de Policía Urbana, Fuentes y cañerías, Caja 295, expediente núm. 226: "D. Manuel Pardo pidiendo licencia para de la cañería general que la conduce a las fuentes públicas de la ciudad tomar el agua necesaria a los usos domésticos de su casa $n^{\circ} 23$ de la calle de la Independencia", 1890.

129. El Diario de Zaragoza, Zaragoza, domingo 26 de enero de 1890, "Arriendo del gran café de la Iberia", p. 3.

130. A.M.Z., Sección de Policía Urbana, Construcción y reedificación de edificios, Caja 292, expediente núm. 1.260: "Emilio C. Samperio solicita permiso para colocar una marquesina de cristales y hierro en la puerta de entrada al Club de Velocipedistas establecido en la calle de la Independencia núm. 25", 1890.

131. A.M.Z., Sección de Policía Urbana, Construcción y reedificación de edificios, Caja 305, expediente núm. 1.380: "D. Manuel Pardo solicita permiso para reformar varios huecos de las casas no 23 y 25 de la calle de la Independencia", 1892.

A causa de estas obras, el cielo raso del café se cubrió por caprichosos dibujos y artísticas pinturas al óleo debidas al pintor Nazario Benedí, y el mobiliario estaba constituido por noventa y dos mesas y veladores con tableros de blanco mármol y sillas y cómodos divanes de roble y oro viejo. Junto al salón principal había otro elegante salón, y por amplios pasillos se entraba al jardín, en cuyo centro había una preciosa cascada. En el piso principal se instaló un salón de billares. El Diario de Zaragoza, Zaragoza, miércoles 28 de diciembre de 1892, "El café de la Iberia", p. 2. 
mente un café, con la denominación también de café de la Iberia (que se abrió al público el 1 de enero de 1893) ${ }^{132}$, que recuperase la fama del antiguo así como la de su jardín, en el que se reunía la distinguida sociedad zaragozana.

En estos renombrados establecimientos continuaban ofreciéndose magníficos conciertos por reputados concertistas (de esta manera, en el café de París, estaban dirigidos por Enrique Malumbres), así como otros espectáculos variados, poniendo de manifiesto que estos cafés estaban al tanto de las últimas novedades. De este modo, en el café Gambrinus se obsequiaba en 1895 (en el "día de moda" -todos los jueves-) a las señoras ${ }^{133}$ y niños que concurriesen a él con una tarjeta que daba derecho a disfrutar de las audiciones del fonógrafo Edison, que tenían lugar todos los sábados desde las seis de la tarde a las doce de la noche ${ }^{134}$.

También alguno de estos establecimientos se involucraba a nivel político y social apoyando las campañas militares del momento. Así sucedió, por ejemplo, en el café de París, en el que se dieron obsequios (café, licores y cigarros) a las tropas expedicionarias zaragozanas destinadas a Cuba y Filipinas, por lo que por esta generosa demostración el consistorio municipal concedió en febrero de 1897 a sus dueños el poder usar el escudo de armas de la ciudad, autorizándoles para que pudieran colocarlo en el establecimiento y en cualquier documento u objeto empleados en su servicio ${ }^{135}$.

En estos años noventa se abrieron nuevos locales, como el café Peninsular (calle de las Escuelas Pías, núm. 11) ${ }^{136}$, el café de Madrid (en las afueras del Portillo, por tanto, alejado del centro de la ciudad) ${ }^{137}$ o el café de Levante (fundado en 1895 por Agustín Charles junto a la Puerta del Carmen -en la actualidad situado en calle de Almagro-) ${ }^{138}$.

132. El Diario de Zaragoza, Zaragoza, domingo 1 de enero de 1893, "Crónica del día", pp. 2-3.

133. Esto pone de manifiesto que ya no eran únicamente los hombres los que frecuentaban los cafés, aunque las señoras acudían sobre todo a estos locales para asistir a conciertos o a otras sesiones de índole similar.

134. El Diario de Zaragoza, Zaragoza, martes 2 de julio de 1895, "Crónica del día", p. 3.

135. A.M.Z., Sección de Gobernación, General e Indiferente, Caja 1.620, expediente núm. 316: "Moción del sr. Mermejo para que se conceda a los dueños del café de París el uso del escudo de la Ciudad por los obsequios que hicieron a las tropas que salieron para Cuba y Filipinas", 1897.

136. El Diario de Zaragoza, Zaragoza, martes 20 de junio de 1893, "Crónica del día", p. 3.

137. El Diario de Zaragoza, Zaragoza, sábado 1 de septiembre de 1894, "Anuncios", p. 4.

138. Agustín Charles abrió un café que se comunicaba con su tienda de ultramarinos (situada junto a la Puerta del Carmen) y que tenía su entrada principal por el paseo de Ronda, también Ilamado paseo de la Lealtad, núm. 4. En 1927 se trasladó a un local emplazado en la planta baja de un inmueble recién construido en paseo de Pamplona núm. 9, donde permaneció hasta 1976. El café, que cerró en ese año, volvió a abrir el 21 de diciembre de 1977 en su nueva y actual ubicación de la calle de Almagro. LAFOZ RABAZA, H., La vida o el Café de Levante. Zaragoza, 1996; y RUIZ MARÍN, J., Zaragoza ayer y hoy. Estampas y noticias. Zaragoza, 2005, p. 220. 
Además de estos cafés, la sociedad zaragozana seguía contando con una amplia oferta de ocio en la ciudad: teatros, casinos, ferial, espectáculos taurinos, programas circenses o gimnásticos y sociedades recreativas y de baile, entre otras formas de esparcimiento. Paralelamente la ciudad recibió la temprana llegada del cinematógrafo, que pronto se convirtió en un espectáculo que tuvo una gran recepción y difusión ${ }^{139}$.

Estos establecimientos fueron reflejo de la ciudad moderna en la que se estaba convirtiendo Zaragoza en esos momentos, y, en concreto, de su transformación urbanística, que habría de proseguir en la centuria siguiente.

Muchos de estos antiguos y prestigiosos cafés ubicados en zonas céntricas y destacadas de la capital aragonesa lograron sobrepasar las fronteras del siglo XX (como el café Suizo ${ }^{140}$, el café de Europa $^{141}$ o el café de la Iberia ${ }^{142}$ ) pero poco a

139. Sobre este tema, véase MARTíNEZ HERRANZ, A., La arquitectura teatral en Zaragoza..., pp. 212-215.

140. Este café desapareció cuando sus locales pasaron a propiedad del Banco Hispano Americano. El 2 de junio de 1916 se procedió, en el café Suizo, a la liquidación de divanes, mesas, grandes espejos, cancelas y ventanas con magníficos cristales grabados, servicios y otros enseres, propios para café. Heraldo de Aragón, Zaragoza, viernes 2 de junio de 1916, "Noticias", p. 4.

Un mes después, el director de la sucursal del Banco Hispano Americano de esta ciudad (hasta ese momento emplazada en calle del Coso, núm. 31), y tras haber sido adquirido recientemente este edificio señalado con el núm. 3 de la plaza de la Constitución y núm. 2 del paseo de la Independencia, solicitó licencia municipal para practicar obras de reforma general en el mismo con el fin de adaptarlo a su nuevo destino, con arreglo a los planos formulados por el arquitecto Miguel Ángel Navarro. A.M.Z., Sección de Fomento, Licencias de obras, Caja 2.013, expediente núm. 2.312: "Mariano Lucas. Director de la Sucursal del Banco Hispano Americano. Obras en plaza de la Constitución, 3 y 2 accoํㄹ del paseo de la Independencia", 1916.

En la actualidad, este amplio local está ocupado por una tienda de cosméticos.

141. El Hotel Europa se mantuvo hasta que en su solar se levantó a comienzos de la década de los treinta un edificio destinado a sucursal del Banco de España (su proyecto se redactó en 1933). A.M.Z., Sección de Fomento, Licencias de obras, Caja 3.070, expediente núm. 3.070: "Ricardo Muñoz Pérez, Director Banco España, construir edificio para Banco en el solar situado en plaza de la Constitución esquina al Coso", 1933.

142. En 1908 el propietario de este café, Manuel Pardo, modificó su distribución y los usos del solar donde estaba emplazado. Esto conllevó que se redujeran sus dimensiones (y que cambiase su nombre por el de café de España, que se mantuvo hasta 1915) y que el resto del terreno, incluido el jardín situado en la parte posterior del inmueble, fueran utilizados para levantar sobre ellos el teatro-cinema Parisiana. Pardo, en abril de 1910, solicitó licencia municipal para verificar en su casa núm. 25 del paseo de la Independencia la apertura de cuatro huecos en la tapia que hacía fachada a la calle de San Clemente y para decorar la portada que ocuparía dos huecos de la fachada al paseo de la Independencia. En el solar de la calle de San Clemente (antiguo jardín del café de la Iberia) se ubicó el Parisiana, que fue inaugurado el 30 de abril de ese año. La entrada principal, los vestíbulos y los pasillos de acceso se situaron en los locales del antiguo café de la Iberia que no habían sido ocupados por el nuevo café de España. La sala de espectáculos y el escenario se construyeron detrás del edificio núm. 25 de Independencia, sobre el espacio del antiguo jardín. A.M.Z., Sección de Fomento, Licencias de obras, Caja 1.064, expediente núm. 794: "Manuel Pardo. Obras, Independencia, 25", 1910. 
poco y hasta mediados del siglo (como el café de Ambos Mundos) fueron desapareciendo (salvo el caso excepcional del café de Levante), al no poder modernizarse y transformarse en la cafetería en boga. En otros casos, estos amplios establecimientos fueron cambiando de propietarios y de denominación (que dada las especificidades de los mismos eran destinados a homónimo destino), como ocurrió con el amplio local ocupado por el antiguo café de E. Flores, en el que se emplazarían posteriormente el café Central (1906) ${ }^{143}$ y, a comienzos de los años treinta, el renombrado café Alaska, que terminaría igualmente desapareciendo.

A ellos se fueron sumando también otros centros a comienzos de la pasada centuria, que terminaron igualmente cerrando sus puertas, entre otros, establecimientos de la talla del café Orienta/ ${ }^{144}$, que, en 1900, se instaló en la planta baja del edificio situado en Coso núm. 39145, que hace esquina con calle de los Mártires (es decir, con la entrada del Tubo). Por tanto, se emplazó en el local que había ocupado el café de Londres hasta ese momento. Así, para este nuevo establecimiento se diseña, como señala $M^{a}$ Pilar Poblador, una nueva portada con elegantes elementos decorativos de estilo modernista ${ }^{146}$; o del café Moderno, situado en 1902 en la planta baja de la casa de la calle del Coso, núm. 17, angular a la calle de Alfonso I, núm. $1^{147}$. Estos cafés no introducen ninguna variación importante respecto al modelo de café conformado en el último cuarto de siglo. Asimismo, se abrieron otros establecimientos no tan céntricos, para atender zonas de recreo de las afueras de la ciudad, como el café fundado el 1 de junio de 1900 por Pablo Salvador en el paseo de Torrero (actual paseo de Sagasta) ${ }^{148}$, con el título de café Terraza de Torrero (posteriormente denominado café Sagasta) ${ }^{149}$, cuya decoración interior fue realizada por el artista aragonés Gil Murillo.

143. Heraldo de Aragón, Zaragoza, jueves 15 de marzo de 1906, "Espectáculos", p. 3.

144. Este café fue inaugurado el viernes 20 de julio de 1900, siendo su propietario Fructuoso Obón. Heraldo de Aragón, Zaragoza, sábado 21 de julio de 1900, "Noticias", p. 2.

145. FORTÚN SOFÍ, R. (dir.), Guía de Zaragoza y de la región aragonesa: anuario para 1902. Zaragoza, 1901, p. 369.

146. El diseño de esta portada de madera es la primera localizada con elementos de raigambre modernista en la ciudad, precediendo a las construcciones arquitectónicas. A.M.Z., Sección de Policía Urbana, Licencias de obras, Caja 577, expediente núm. 642: "D. Fructuoso Obón pidiendo permiso para abrir un hueco para ventanas dentro de un rehundido de puerta en la fachada de la casa no 39 de la calle del Coso por la de los Mártires, y construir una portada en el cuerpo bajo de ambas fachadas con puertas de acero ondulado", 1900.

Para este tema, véase POBLADOR MUGA, M. ํㅗ. P., "El Modernismo en la arquitectura y en las artes". Argensola 114 (2004), pp. 13-62 (espec. p. 43).

147. Este café abrió sus puertas el 1 de octubre de 1902 y en su decoración interior estaban presentes elementos decorativos de la estética modernista. El Diario de Zaragoza, Zaragoza, miércoles 1 de octubre de 1902, "El Café Moderno", p. 1.

148. Heraldo de Aragón, Zaragoza, sábado 2 de junio de 1900, "Noticias", p. 3.

149. Heraldo de Aragón, Zaragoza, domingo 3 de septiembre de 1911, p. 2. Este café estaba emplazado en paseo de Sagasta, núm. 29, y en él se servía cerveza de la fábrica "La Zaragozana". 
Con ellos se perdieron los sugestivos locales en los que transcurrían las horas plácidas y lentas, dejando un vacío que no ha podido ser sustituido por los actuales que han pasado a ser meros lugares de paso. Con ellos desaparecieron el deleitoso aroma a café tostado, los espejos profundos en los que se asomaba el pasado y reposaba el humo, y, especialmente, la intimidad y sosiego necesarios para la celebración de tertulias y encuentros de peñas fijas de estudiantes, poetas, artistas y escritores, o de los jugadores de dominó o ajedrez. Por tanto, el café clásico fue perdiendo paulatinamente (sobre todo a partir de los años veinte cuando comienza a cambiar el concepto del esparcimiento colectivo y de espacio de reunión) peso en la vida ciudadana y muchas de las relaciones que hasta entonces se desarrollaban en ellos se desplazaron, principalmente a partir de los cincuenta de la pasada centuria (con el inicio de la fiebre modernizadora), a otros ámbitos, se redefinieron o desaparecieron.

Cerramos estas líneas con el recuerdo con el que José Blasco ljazo evocaba estos viejos y agradables lugares, que fueron uno de los ejes de la vida cultural zaragozana:

Andando el tiempo, la decadencia del parlamentarismo trajo la decadencia del Café y nació el bar que es una manera de discurrir de pie y con prisa [...]. Los hombres que no estudian ni leen ¿qué pueden saber ahora sin la enseñanza del Café?

Al Café se acudió antes, no sólo a tomar la degustación sino a conversar, a observar, a opinar, a discutir, a dar lecciones, y a propagar noticias... ¡ Las cosas que se habrán arreglado en el Café! [...]. Porque los habituales del Café constituyen una enciclopedia humana y porque no existe tema de la vida, de las artes y ciencias, que no se plantee en torno a una mesa de café1 ${ }^{150}$.

150. BLASCO IJAZO, J., Zaragoza y sus locales de espectáculos. Los que fueron y los que son. Casi dos siglos de curiosa historia 1764-1945. Zaragoza, 1945, p. 82. 